\title{
Twin Screw Extruders as Continuous Mixers for Thermal Processing: a Technical and Historical Perspective
}

\author{
Charlie Martin ${ }^{1,2}$
}

Received 22 December 2015; accepted 15 January 2016; published online 16 February 2016

\begin{abstract}
Developed approximately 100 years ago for natural rubber/plastics applications, processes via twin screw extrusion (TSE) now generate some of the most cutting-edge drug delivery systems available. After 25 or so years of usage in pharmaceutical environments, it has become evident why TSE processing offers significant advantages as compared to other manufacturing techniques. The wellcharacterized nature of the TSE process lends itself to ease of scale-up and process optimization while also affording the benefits of continuous manufacturing. Interestingly, the evolution of twin screw extrusion for pharmaceutical products has followed a similar path as previously trodden by plastics processing pioneers. Almost every plastic has been processed at some stage in the manufacturing train on a twin screw extruder, which is utilized to mix materials together to impart desired properties into a final part. The evolution of processing via TSEs since the early/mid 1900s is recounted for plastics and also for pharmaceuticals from the late 1980s until today. The similarities are apparent. The basic theory and development of continuous mixing via corotating and counterrotating TSEs for plastics and drug is also described. The similarities between plastics and pharmaceutical applications are striking. The superior mixing characteristics inherent with a TSE have allowed this device to dominate other continuous mixers and spurred intensive development efforts and experimentation that spawned highly engineered formulations for the commodity and high-tech plastic products we use every day. Today, twin screw extrusion is a battle hardened, well-proven, manufacturing process that has been validated in 24-h/day industrial settings. The same thing is happening today with new extrusion technologies being applied to advanced drug delivery systems to facilitate commodity, targeted, and alternative delivery systems. It seems that the "extrusion evolution" will continue for wide-ranging pharmaceutical products.
\end{abstract}

KEY WORDS: amorphous solid dispersion; continuous manufacturing; continuous mixing; twin screw extrusion.

\section{INTRODUCTION}

If the old saying "the best indication of future performance is past performance" holds true, then the future for twin screw extrusion to develop and manufacture dosage forms will eventually dominate the pharmaceutical manufacturing landscape for new drug entities. Developed almost 100 years ago for food and natural rubber/plastics applications, twin screw extrusion (TSE) now generates some of the most cutting-edge drug delivery systems available.

Polymers are specified to function as thermal binders and act as drug depots and/or drug release retardants upon cooling and solidification. This means active pharmaceutical ingredients (APIs) need to be intimately mixed with a wide range of excipients. There are many mixing devices, but it will become evident that TSE processing offers significant advantages as

\footnotetext{
${ }^{1}$ Leistritz Extrusion, Leistritz North America, 175 Meister Avenue, Somerville, New Jersey 08876, USA.

${ }^{2}$ To whom correspondence should be addressed. (e-mail: cmartin@leistritz-extrusion.com)
}

compared to batch manufacturing techniques. An advantage is that solvents and water are generally not necessary for processing, which reduces the number of processing steps because expensive drying equipment and time-consuming drying steps can be eliminated.

After 100 or so years of usage, the well-characterized nature of the TSE process lends itself to ease of scale-up and process optimization while also affording the benefits of continuous manufacturing and adaptability to process analytical technology in an ever-changing regulatory and fiscal environment. What's occurring today for pharmaceuticals with regard to the implementation of extrusion technology to increase efficiencies and save costs is analog to what occurred 80 or so years ago in the plastics and food sectors of industry as batch processes were replaced by continuous manufacturing alternatives for reasons that are now obvious.

Almost every plastic has been processed at some stage in the manufacturing train on a twin screw extruder to mix materials to impart desired properties into a final part. Plastics is a major worldwide industry that plays a role in all facets of modern life, from health and well-being, nutrition, shelter and 
transportation to safety and security, communication, sports, and leisure activities. Twin screw extrusion is used to make products we use every day such as packaging films, fibers for carpets, car interiors and windshields, to higher-tech products like structural decking, space-shuttle parts, conductive parts, and even synthetic wine corks. These are all high-tech products!

This ability to mix materials to customize product performance caused visionary pharmaceutical scientists to consider extrusion to enable therapies of poorly soluble compounds through the generation of amorphous solid dispersions. The embrace by the scientific community of melt extrusion has led to further research efforts and understanding of how the technology can be applied, and resulted in traditional plastics process techniques being transferred to manufacture novel dosage forms and unique multifunctional medical devices. It is now a fact that TSE can produce reliable and robust drug product manufacturing alternatives and show unlimited potential for new, novel dosage forms.

This review article presents a historical and technical perspective of extrusion technology. It becomes evident, based on the history of TSE in other markets, that the use of twin screw extruders will assume a dominant role manufacturing methodology in the pharmaceutical marketplace.

\section{EVOLUTION OF BATCH TO CONTINUOUS AND SINGLE TO TWIN SCREW EXTRUDERS IN PLASTICS INDUSTRY}

The earliest commercial machines for mixing food and polymer melts (natural rubbers) were batch mixers with the first major mixer, a two-roll mill, described in an 1836 patent. A side view of a two-roll mill is presented in Fig. 1. It was not until the early twentieth century that batch mixer designs stabilized with a ram containing internal mixers. These were the same batch mixing devices that dominated polymer and food industries into the 1960s. A side view of a conventional batch mixer is presented in Fig. 2. Batch mixers are vessels in which polymers, oils, fillers, and additives are measured, introduced, and operated in an unfilled and largely unpressurized manner. In a starved unpressurized mixing chamber, the compounds may avoid the locally pressurized region of high shear between the rotor blades and chamber wall, which can result in a compound that has a wide distribution in states of agglomerate breakup and distribution. By definition, batch mixers are "large mass" discontinuous mixers.

Processing technologies that used single screw pumping devices began to commonly appear in the mid/late 1800s for products such as pasta, soap, and ceramic materials and reflected the transition that was underway from batch to continuous processing. A schematic diagram of a single screw extruder is presented in Fig. 3. Why did this transition take place? Early issues were primarily relating to "product quality," as evidenced by a patent on screw extrusion by Gray [1879; British Patent \#5056] that involved extruding thermoplastic products for wire coating that argues that the quality of the insulation properties was better than produced by a ram (batch) extruder. Interestingly, the issue of higher production rates was not raised, suggesting that improved pumping consistencies and quality drove the invention.
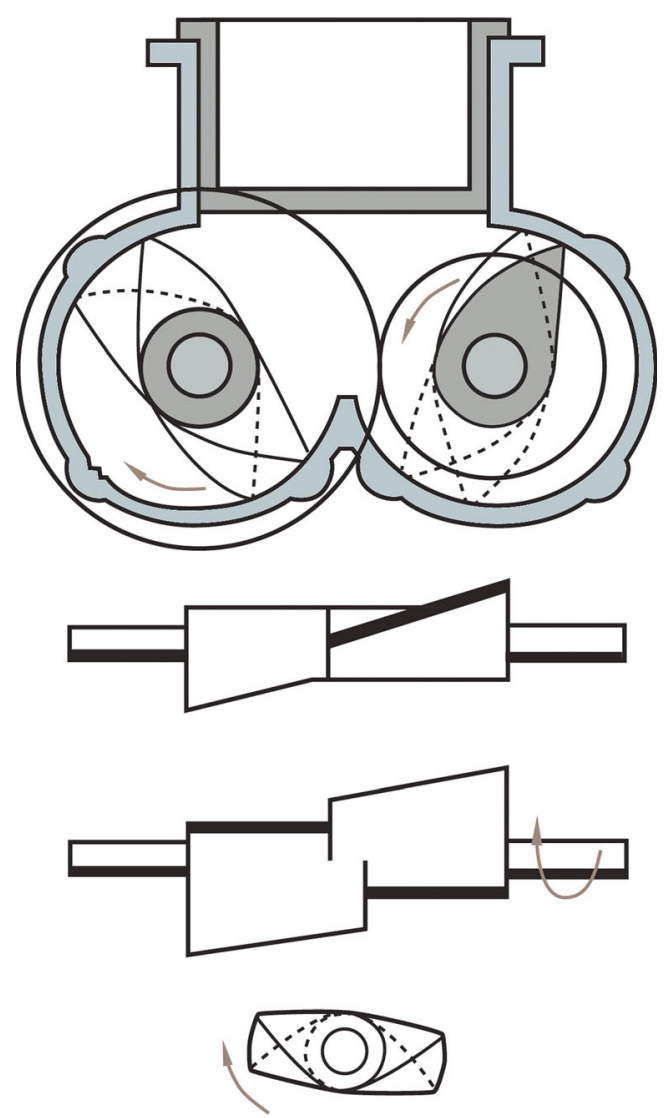

Fig. 1. Side view of a two-roll mill

In the mid 1800 s, continuous mixing machines were beginning to be used but seemingly were not widely commercialized. Continuous mixers began appearing in patent literature from the 1920 s to the 1960s; however, it was only during the second half of the twentieth century that twin screw extruders were accepted as the continuous mixer that most often produced a higher quality, more uniform mix at reduced mixing/residence times and localized temperatures. The comparatively first-in, first-out nature of the TSE also meant that the materials experienced a more uniform heat/shear history as compared to available batch type devices.

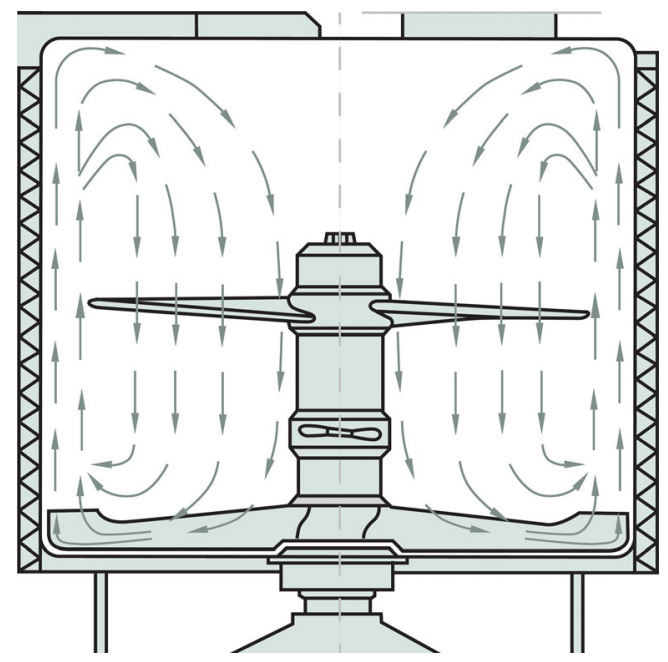

Fig. 2. Side view of a conventional batch mixer 


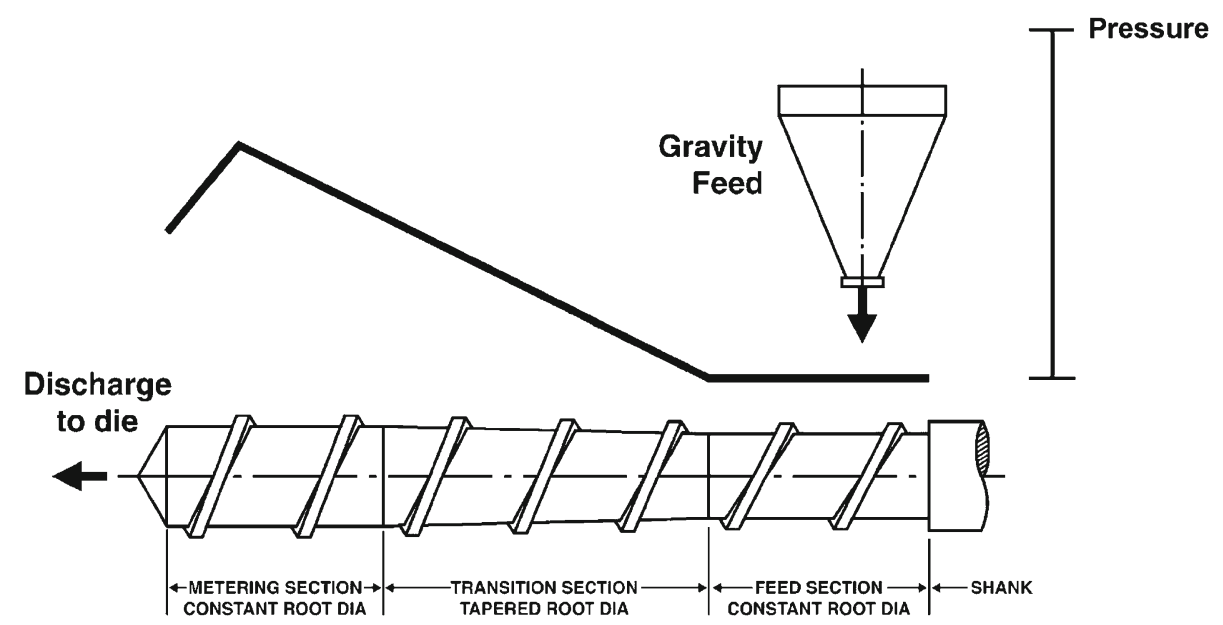

Fig. 3. Single screw extruder screw design with flood fed feed throat and the associated pressure/pumping profile

In the 1950s and 1960s, a lot of work was performed using single screw extruders, with some success. A single screw extruder, as the name implies, uses a one-piece screw inside a one-piece barrel driven by a motor/gearbox - a much simpler design as compared to a twin screw extruder. In the 1970s, a tipping point occurred and much of the food/plastic industries transitioned from batch to continuous processing, primarily via twin screw extrusion. A photograph of a 1960s era twin screw extruder is presented in Fig. 4. The screw design of early stage counterrotating intermeshing twin screw is shown in Fig. 5. Interestingly, the processing section shrouding is similar to what is used in today's twin screw extruder for pharmaceutical applications.

In the early 1980s, the TSE became the most preferred continuous mixer used in plastics, primarily because TSEs are better mixers than single screw extruders (SSEs) due to several features relating to interscrew interactions that make it significantly easier to successfully compound a formulation. That being said, the SSE maintains its place for low-intensity mixing applications and high-pressure pumping, which is why this device makes most of the extruded items we see and use every day, i.e., drinking straws and packaging film (2).

During this time frame (1980s and 1990s), research activities on polymer mixing intensified at universities and research institutions such as the University of Akron, Polymer Processing Institute, and Ecole Polytechnique, to name a few. Exhaustive mixing studies were performed, thousands of papers were published, and many millions of dollars were invested in

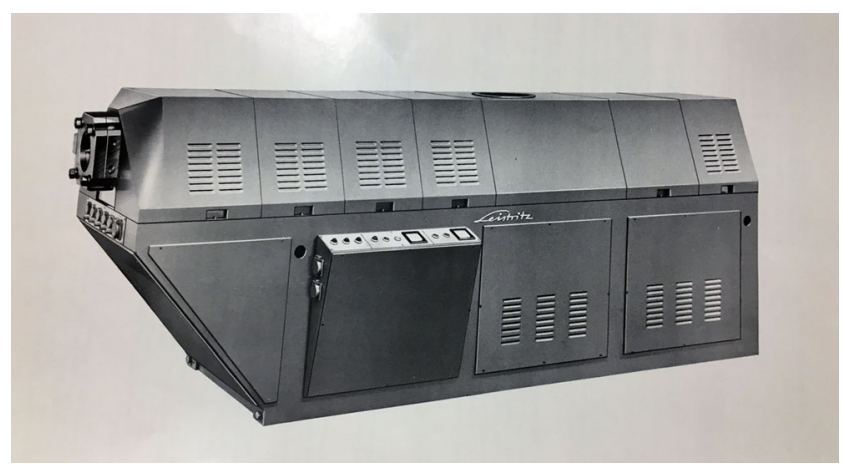

Fig. 4. Photo of a 1960s era twin screw extruder developing (and marketing) the "ultimate" continuous mixer. By the mid/late 1990s, the twin screw extruder was deemed the device of choice for most mixing and many devolatilization processes.

Today, the TSE continues to dominate the market for continuous mixing and devolatilization, and the SSE for high-pressure pumping for the extrusion of parts such as film, sheet, profiles, tubes, fibers, coatings, etc. Interestingly, in terms of the number of units currently installed each year, there are approximately ten times as many SSEs as compared to TSEs, implying that there are still opportunities for the usage of SSEs for therapeutic drug delivery systems, particularly for multifunctional medical devices (3).

\section{BASICS FOR TWIN SCREW EXTRUDER}

\section{Screw Elements}

The same process tasks are performed in any TSE. Initially, materials are metered into the extruder feed throat and solids conveying occurs. The materials being processed must pass through a series of pressurized, fully filled mixing regions. The materials are melted via mixing elements and conveyed via flighted elements. Flighted elements discharge the melt through a die or other pressure-generating device into various shapes for downstream processing.

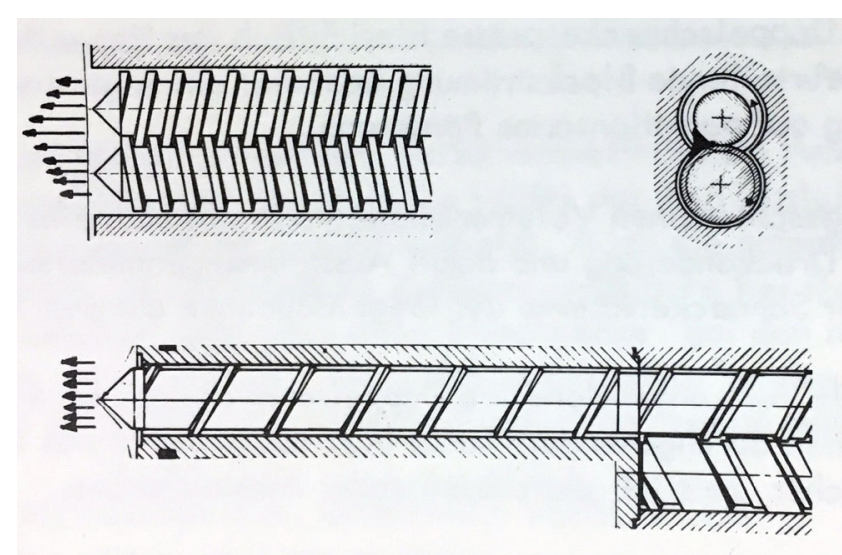

Fig. 5. Screw design of early stage counterrotating intermeshing TSEs 
At the heart of any TSE process sections are the rotating screws contained within barrels. Screws are typically segmented and assembled on shafts, in which case the torque transmitted to the shaft is the limiting factor for the amount of power/torque that is available to process materials. Screws for TSEs can also be a one-piece design with significantly higher torque transmittal possibilities.

The OD/ID ratio (outside screw diameter/inside screw diameter) and channel depth are important TSE design parameters as these parameters dictate the available free volume and torque. A graphic illustration of the outer diameter, inner diameter, and flight depth of screw elements is presented in Fig. 6. As the channel depth increases, the ID decreases and results in less attainable shaft torque. An optimum balance between free volume and torque is important as both represent boundary conditions that may limit attainable material throughput rates.

A TSE is generally referred to by the diameter of screws. For instance, a "ZSE-18" model would reflect a TSE with an 18mm screw outside diameter, or OD, for each screw. In the plastics and food industries, ODs range from 12 to 400+ mm with outputs from $50 \mathrm{~g}$ to greater than $50,000 \mathrm{~kg} / \mathrm{h}$. Pharmaceutical TSEs are generally in the 60-70-mm class and below, with research and development efforts performed on TSEs with screw ODs in the 10-30-mm range. Flight depths range from as little as 1 to $3 \mathrm{~mm}$ on a small lab extruder to approximately $15 \mathrm{~mm}$ on a $70-\mathrm{mm}$ class machine. Even a 140-mm class TSE will only have a flight depth in the 25-mm range, hence the term "small mass" continuous mixer with short mass transfer distances.

There are seemingly an infinite number of possible screw variations. There are, however, only three basic types of screw elements: flighted elements, mixing elements, and zoning elements. Flighted elements forward material past barrel ports, through mixers, and out of the extruder through a die. Mixing elements facilitate the mixing of the various components being processed. Zoning elements isolate two operations. Some elements can be multifunctional.

Flighted elements are available with various angles for different conveyance attributes, depending upon the location placement (Fig. 7). The higher the pitch of the flight angle, the faster it pumps. Higher volume feed elements and slotted elements that both pump and mix are available and matched to the unit operations as dictated by the process (4).

Kneading elements, the most common mixing elements, are strategically placed along the length of the screws (Fig. 8). Wider kneaders cause extensional mixing and planar shear to a

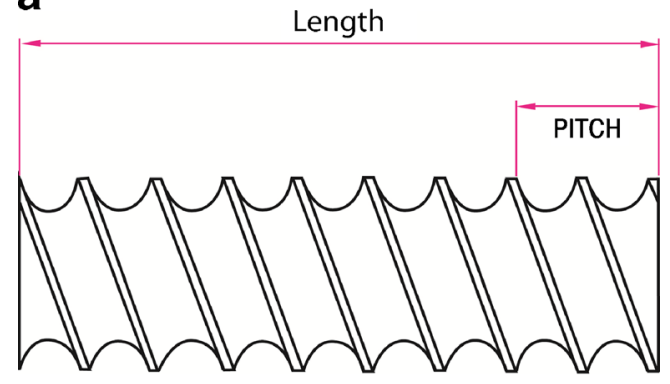

b

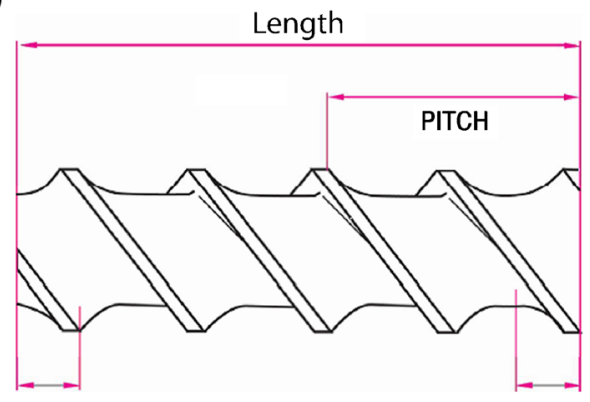

C

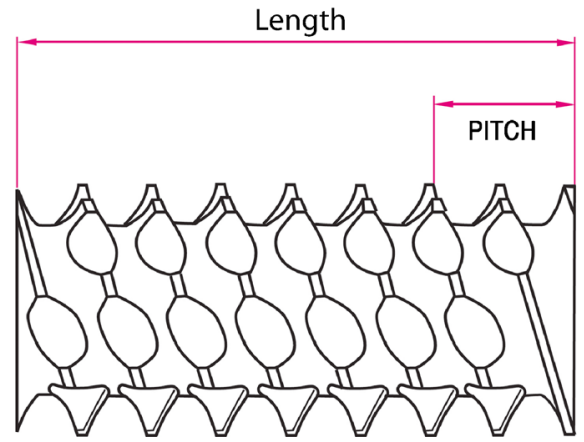

Fig. 7. a-c Examples of flighted elements. a Small pitch conveying element; b large pitch conveying element; c slotted mixing/conveying element

be imparted into the materials being processed and are more dispersive in nature as compared to narrow kneaders that result in divisions and recombination of melt streams and, therefore, facilitate distributive mixing. Other parameters

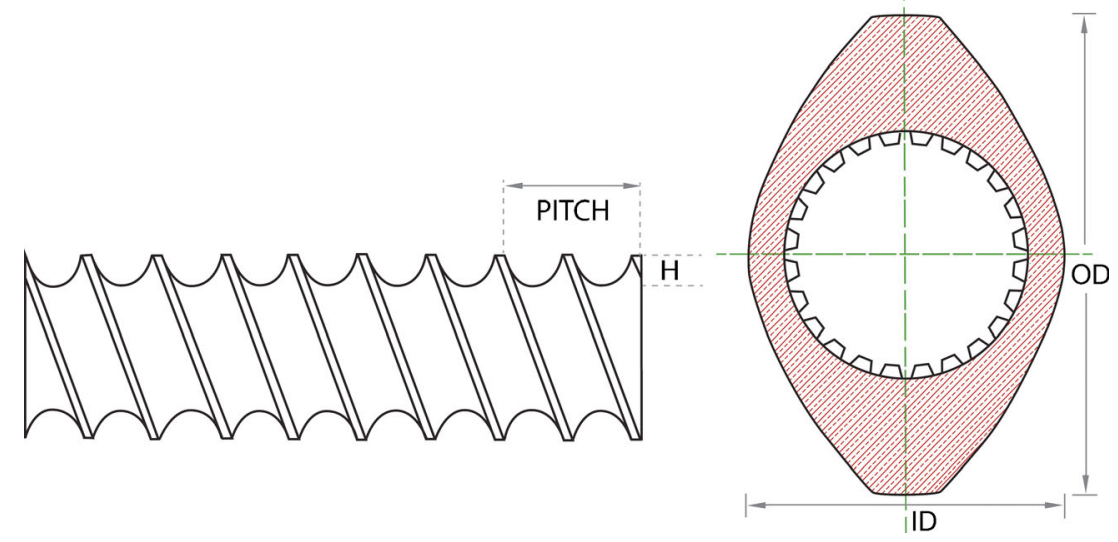

Fig. 6. Illustration of pitch, outer diameter $(O D)$, and inner diameter (ID) 

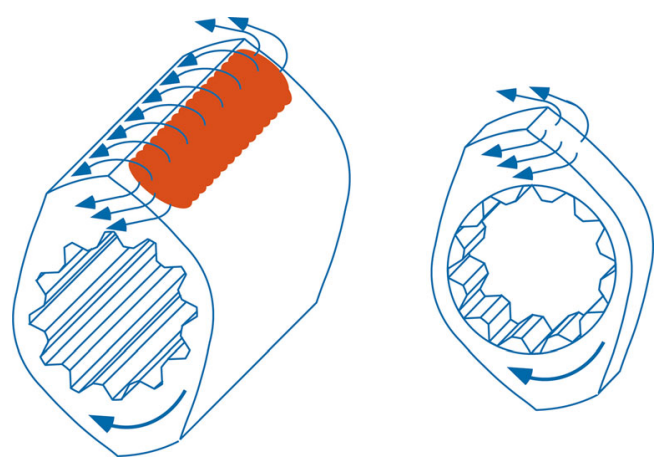

Fig. 8. Examples of mixing (kneading) elements

regulating mixing intensity include the offset angle of the kneaders $\left(30,60^{\circ}\right.$ forward or reverse) or neutral $\left(90^{\circ}\right)$. It should be noted that an innumerable number of mixing elements (i.e., rotors, slotted vanes, and blister rings) are available but that the kneading type elements account for $90 \%+$ of those used in a corotating TSE.

Another variable in the geometry of mixing elements is the "lobe count." The lobe count refers to the number of screw tips/ flights that are wiping the barrel wall. The OD/ID ratio and the mode of operation determine the number of lobes that are geometrically possible for a given design. Examples of bilobal and trilobal TSE screw elements are presented in Fig. 9. Most corotating intermeshing TSEs are bilobal due to interference issues, and a corotating intermeshing TSE is limited to two lobes at typical OD/ID ratios (1.4 to 1.7/1). For laboratory applications, a 1.2/1 OD/ID can be specified and three lobes can be used to facilitate low free volumes and high-torque for testing $20 \mathrm{~g}$ batches, or less.

\section{Fundamentals of Mixing}

There are two main types of mixing: distributive mixing and dispersive mixing. Distributive mixing involves melt division and
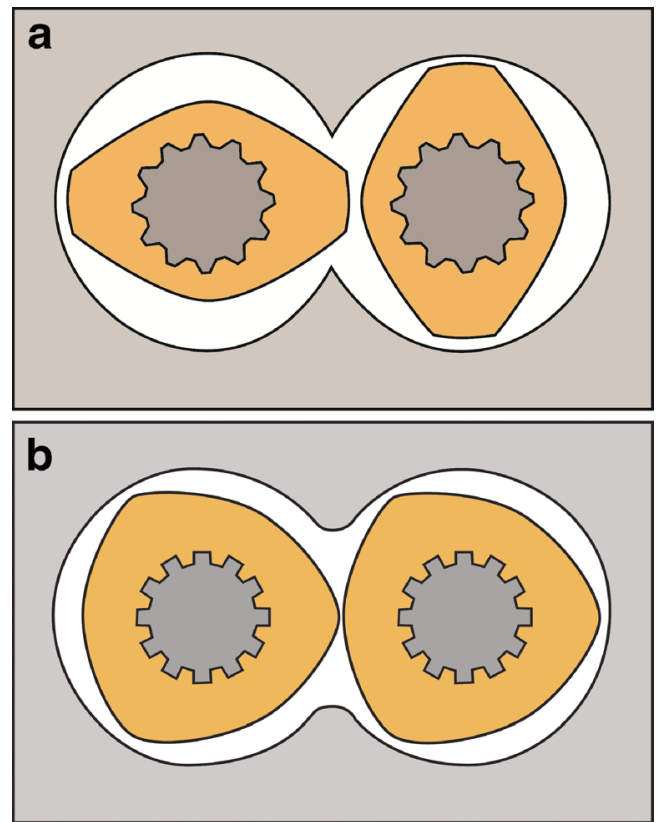

Fig. 9. a Example of bilobal TSE screw elements; b Example of trilobal TSE screw elements

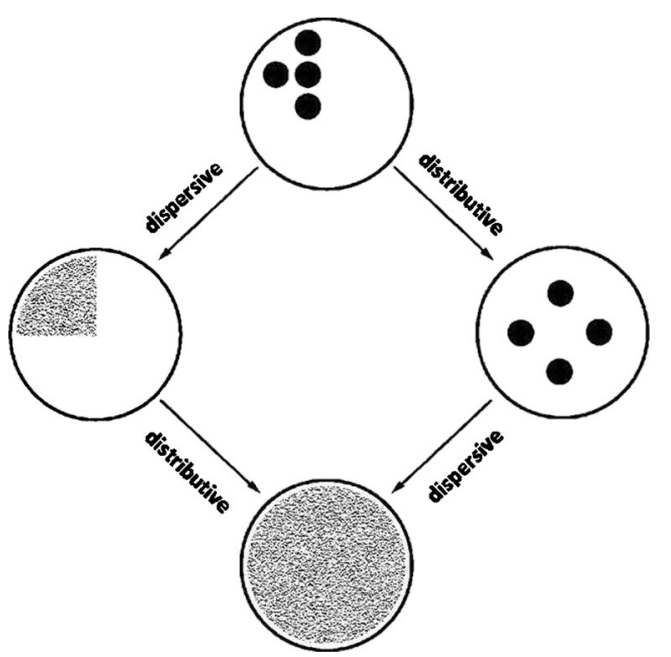

Fig. 10. Graphic illustration of distributive and dispersive mixing

recombination, while dispersive mixing involves shear and elongational mixing. A graphic illustration of two types of mixing is presented in Fig. 10. Screw designs can be made shear intensive and/or passive, based upon the elements specified in the design. Mixing elements may be dispersive, distributive, or a balance of each/both. Screw elements that accentuate extensional mixing and planar shear effects are dispersive in nature, as compared to elements that facilitate melt divisions/recombinations, which are more distributive and therefore useful for mixing heat and shear sensitive materials. Shear-sensitive APIs are often distributed in a melt and then allowed to dissolve into the polymer matrix before exiting the TSE, whereas more severe dispersive mixing is sometimes needed. Other factors that dictate mixing intensity include, but are not limited to, the screws' rpm, the gaps between the screws and screw flight/ barrel wall, and the "lobe count."

In a TSE, the materials being processed are bounded by screw flights and barrel walls, often referred to as the melt pool. The materials are separated into small melt pools by screw flights and barrel walls, which is why the TSE is by definition a "small mass" continuous mixer, as compared to the large mass batch mixer described earlier. As shown in Fig. 11, there are five shear regions in the screws for any TSE, regardless of screw rotation or degree of intermesh. The following is a brief description of each shear region.

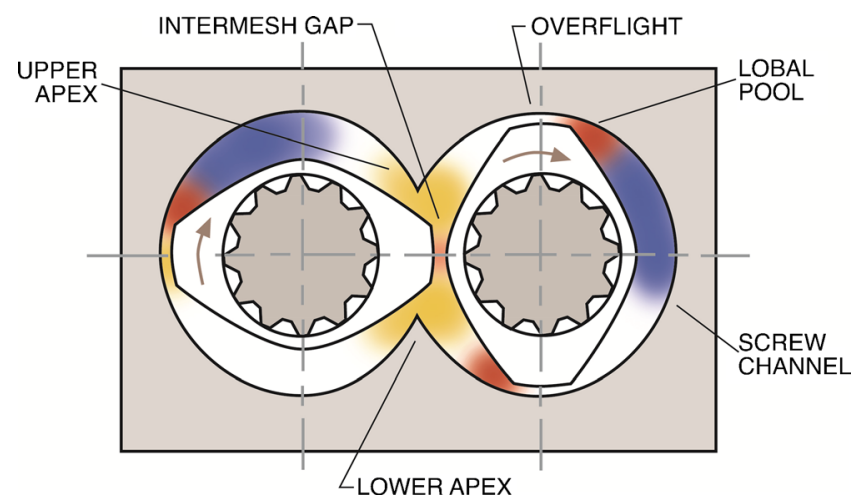

Fig. 11. Cross section view of TSE screw denoting five shear regions 
Screw channel a low shear region, highly dependent on the degree of screw fill in a starved TSE; shear is significantly lower as compared to the other shear regions.

Overflight/tip a high shear region, independent of the degree of screw fill, located between the screw tip and the barrel wall; the material undergoes significant planar shear effects.

Lobal pool a high shear region, independent of the degree of screw fill, the compression/ acceleration entering into the overflight region; the material experiences a particularly effective extensional mixing effect.

Apex (top/bottom) a high shear region, independent of the degree of screw fill, where the interaction from the second screw results in compression/decompression/extensional effects associated with pressure fields and directional flow changes that result in increased mixing rates.

Intermesh a high shear region, independent of the degree of screw fill; it is a high-intensity mixing zone between the screws where the screws "wipe" each other.

As shown in Fig. 12, each screw, to a degree, wipes the other in a corotating twin screw extruder. This is termed "self-wiping." This self-wiping effect sequences unit operations and discharges the small volume of materials in a first-in, first-out sequence with a given residence time distribution (RTD). This results in a uniform deformation/mixing history, and depending on the length and screw design of the TSE, there will be an associated RTD for the process section. The more filled the screws, the tighter the RTD, and the more starved the screws, the wider the RTD. An illustration of the effect of the degree of screw fill on the residence time distribution is presented in Fig. 13.

For simplicity, the four high mass transfer regions shown in Fig. 11 can be viewed as independent of the degree of screw fill, which is why, in a starve-fed machine, when rate is decreased at a given screw rpm, more mixing occurs due to a longer residence time in the mixing zones. Alternatively, as rate increases at a given screw rpm, the low shear channel region plays a larger role and the materials pass over the mixing zones quicker, and therefore, there is shorter exposure time to high shear regions and less lobal mixing events.

The intense mixing associated with the short interscrew mass transfer characteristics inherent with a TSE small mass continuous mixer results in highly efficient distributive and/or

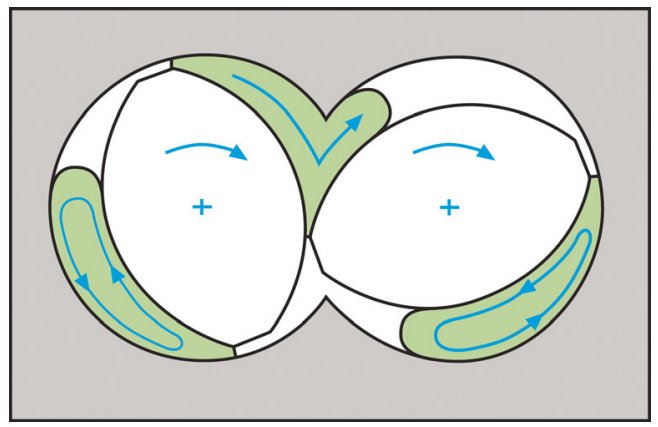

Fig. 12. Self-wiping flow effect in a corotating TSE

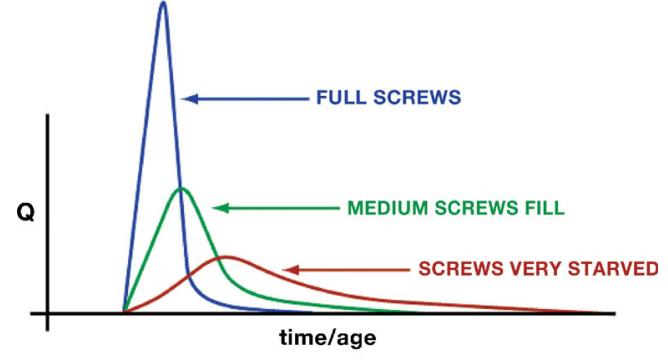

FULL SCREWS $=$ good pump/less mass transfer EMPTY SCREWS = poor pump/more mass transfer

Fig. 13. Effect of the degree of fill on the residence time distribution in a TSE

dispersive mixing that results in a more uniform product as compared to large mass batch mixers. Entrapped air, moisture, and volatiles are also removed via venting. The short residence time associated with a TSE, as compared to a batch process, is beneficial for many heat/shear-sensitive materials, as the TSE can be designed to limit exposure to elevated temperatures to just a few seconds. RTs range from as short as $5 \mathrm{~s}$ to as long as 6 to $10 \mathrm{~min}$, with most processes operating in the 20 - to 60 -s range.

Residence time is a challenging parameter to calculate, because the process in a TSE is a combination of partially and fully filled zones. It is common to use two separate equations making assumptions based on the screw design and processing conditions with regard to filled/unfilled sections. In lieu of access to computer modeling, the RT can be estimated as follows (5):

Residence of for fully filled sections of length $L_{\mathrm{f}}$ :

$\Phi_{\mathrm{f}}=\frac{3.08 \times L_{\mathrm{f}} \times h \times D}{Q}$

Where:

$\Phi_{\mathrm{f}}$ the residence time in seconds

$L_{\mathrm{f}}$ length of the section in centimeters

$h$ overflight gap screw tip to barrel wall in centimeters

$D$ screw diameter in centimeters

$Q$ volumetric flow rate in cubic centimeter per second

Residence of for starved sections of length $L_{\mathrm{s}}$ :

$\Phi_{\mathrm{s}}=\frac{2 \times L_{\mathrm{s}}}{Z N}$

Where:

$\Phi_{\mathrm{S}}$ the residence time in seconds

$L_{\mathrm{S}}$ length of the section in centimeters

$Z$ flight pitch in centimeters

$N$ screw speed in rotations per minute

The residence times for the filled and unfilled sections are then simply added together to estimate the total residence time in the extruder.

Viscosity of the melt also plays a role in mixing. Temperature control, thereby managing the viscosity of the melt, and 
the staging of elements are also factors. During solid resin melting, viscosity is at its highest so high stress rates are possible, which results in dispersive mixing but can also cause degradation. In the latter stages of TSE process section, lower viscosities yield lower stress rates that may enable heat and shear APIs to be mixed without degradation (6).

The following simple formula provides insight into the different variables impacting peak shear stress.

Peak shear stress $=\frac{\pi \times D \times n}{h \times 60} \times$ Viscosity

$D$ screw diameter

$N$ screw speed in revolutions per minute

$h$ overflight gap screw tip to barrel wall

\section{Barrel}

The barrel section of a twin screw extruder is available in these basic configurations: solid feed, liquid feed, side feed, venting, and closed segments. Each section serves a specific functionality and allows for multiple unit operations when combined with the desired screw design. Closed barrel zones generally represent the majority of processing length for any TSE and are placed at high-pressure compounding and/or pumping locations. Examples include mixing, kneading, or pumping to the die.

The length of the TSE process section is described in terms of the length to diameter $(L / D)$ ratio and defined by dividing the overall length of the process section by the diameter of the

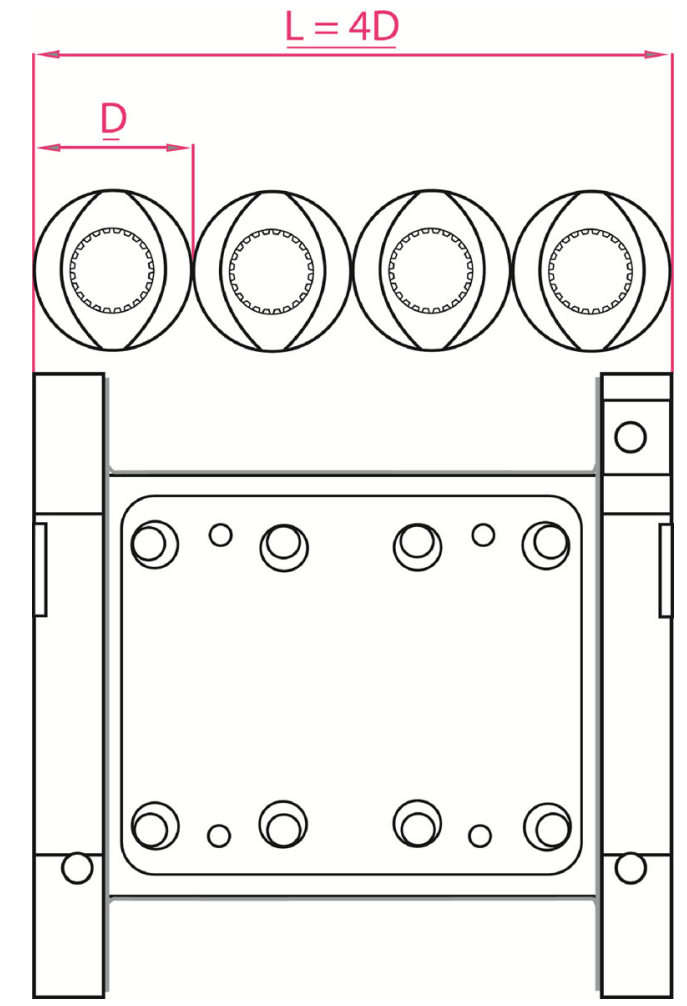

Fig. 14. Length to diameter ratio for a TSE barrel section; this barrel section has a $4: 1 L / D$ screws. An example of a barrel of $4 / 1 L / D$ is presented in Fig. 14. For instance, if the OD of a screw is $20 \mathrm{~mm}$ and the length of the process section is $800 \mathrm{~mm}$, then the $L / D$ ratio is $800 / 20$ or $40 / 1 L / D$. If the length was $400 \mathrm{~mm}$, the $L / D$ would be $400 / 20$ or $20 / 1 L / D$. Higher $L / D$ values result in a longer process section that can support more unit operations (7).

The $L / D$ and staging of barrel and screws are dictated based upon the number of unit operations to be performed. For example, a system requiring only compounding of drug and polymer with moisture removal and pumping to a die might be conducted in a 20:1 L/D configuration. Comparatively, a 40:1 $L / D$ configuration might be required for a plasticizer injection, compounding of polymer with plasticizer, API addition via side stuffing, or moisture removal and pumping. Multistage venting and/or foaming processes might even require tandem extrusion systems that link together multiple extruders to string together and resolve conflicting unit operations, such as high-intensity mixing combined with using a second extruder as a heat exchanger to cool the melt. A setup of twin screw extruder for high-intensity mixing mated to a single screw as a cooling and pumping device is presented in Fig. 15.

\section{Feeder}

The feed system to a TSE typically sets the rate to the TSE and maintains formulation accuracy. Various delivery mechanisms are used, including vibratory trays and single screw and twin screw augers. Loss-in-weight (LIW) feeders maintain a constant mass flow rate to the TSE by adjusting the feed mechanism via a tuning algorithm based on material usage from the hopper that is situated on a load cell (Fig. 16). When multiple feed streams are being introduced, the TSE process section LIW feeders will maintain formulation accuracy. Liquid feed streams use a piston or gear pump, depending upon the viscosity of the liquid. Crammer feeders can also be used for highly filled and/or fluffy materials.

The TSE is starve-fed with the screws' rpms being independent from the feed rate and used to optimize process

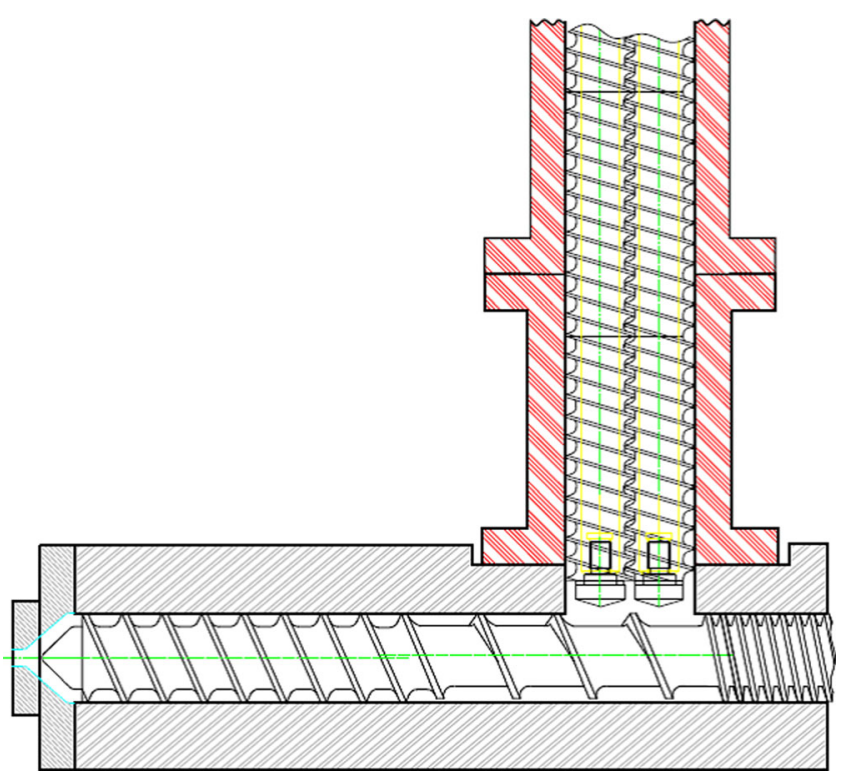

Fig. 15. Paring up a twin screw extruder for high-intensity mixing with a single screw extruder for cooling and pumping 


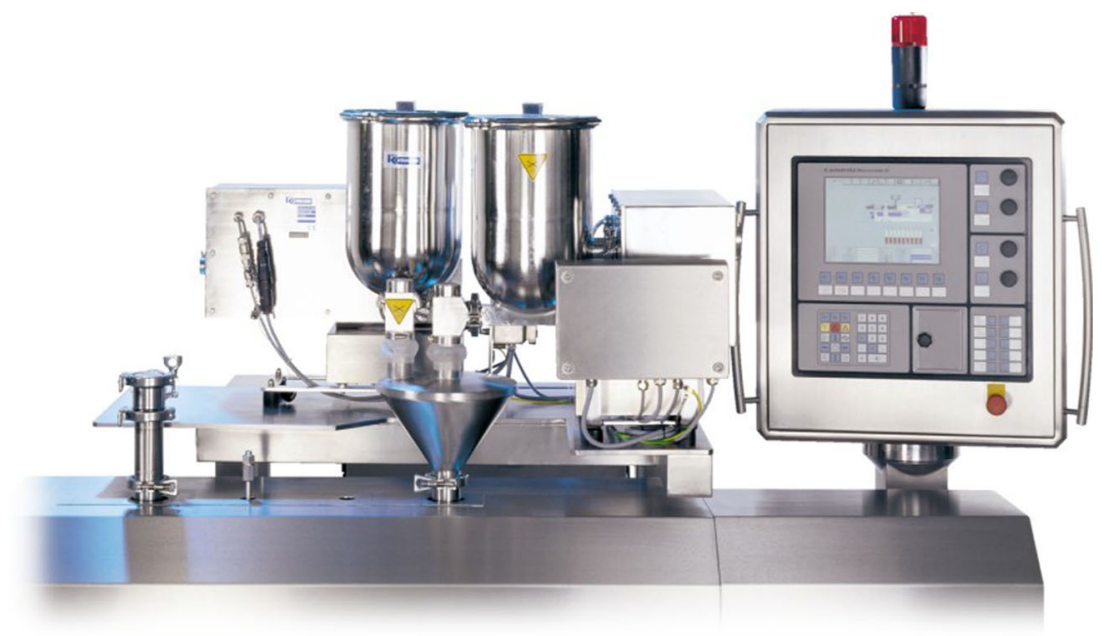

Fig. 16. Setup of multiple loss-in-weight feeders to meter excipients and APIs into a TSE

efficiencies. The pressure gradient in the twin screw extruder is determined by the selection of screws and operating conditions (rate vs. screw rpm). Flighted elements are strategically placed so that the screw channels are not filled which results in a zero pressure underneath downstream vent/feed sections, which facilitates downstream feeding of materials and prevents vent flooding (Fig. 17).

The downstream addition of materials into a melt stream is often facilitated by a side stuffer, as shown in Fig. 18. A side stuffer is a corotating, intermeshing twin screw auger that "pushes" material into the process melt stream to allow for avoidance of the high shear region associated with melting and also reducing residence time exposure for heat-sensitive materials. Liquid feed points also allow for the introduction of liquids or molten materials downstream in the process. Sequential feeding may also eliminate the need for premixing prior to extrusion (8).

\section{Gearbox}

The TSE gearbox transmits energy from the motor to the screws and reduces the motor speed to the desired screws' rpm while multiplying torque, maintaining angular timing of the screws, and accepting the thrust load from pressure being generated from the process. To avoid damage, a mechanical overtorque coupling connects the motor shaft to the gearbox input shaft that automatically disengages at a designated level.

\section{Devolatilization}

Another common usage for a TSE is for devolatilization (DV), which is a process to remove various amounts of gases from the process melt including but not limited to residual solvents, water, and other undesirable volatile contaminants. Vent zones facilitate the removal of volatiles from the melt stream. The venting process may also be performed under vacuum and may occur at a series of positions along the length of the TSE process section. Using multiple venting locations, it is possible to remove substantial quantities of volatiles from the melt stream, i.e., $30 \%+$.

Devolatilization efficiencies in a TSE can be improved with a longer residence time under the vents, higher surface area of the melt, higher surface renewal, more nucleation, growth and rupture of bubbles, higher vacuum level, and use of stripping agents to facilitate bubble formation (9).

\section{Pressure Generation}

Elevated pressure at the die is needed to push polymer melt through the die into various shapes for downstream

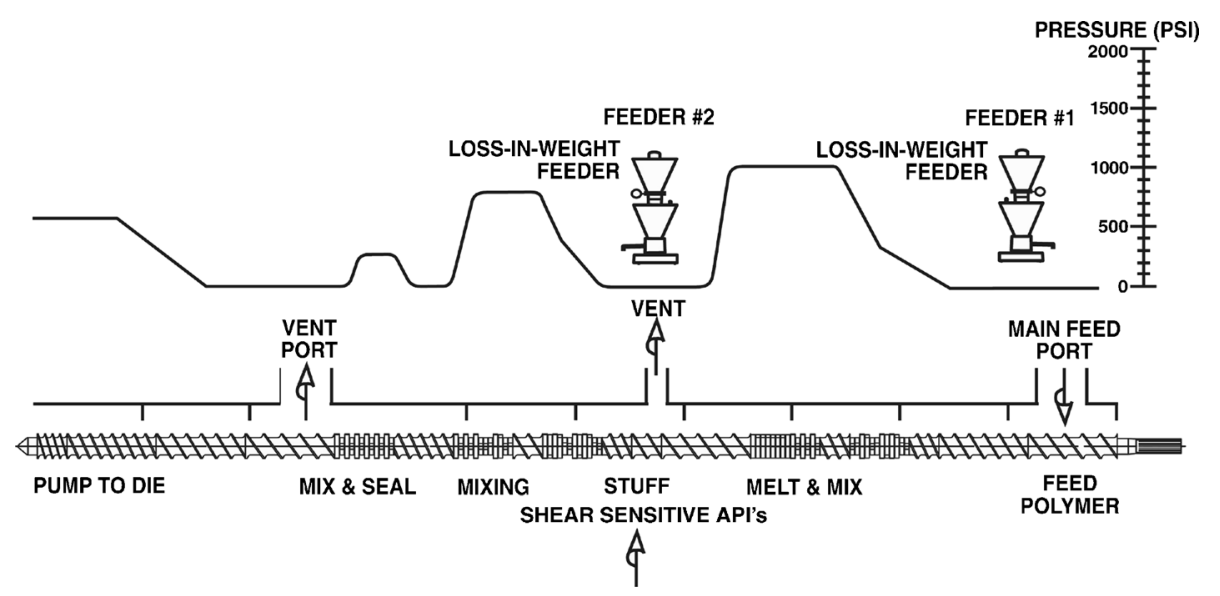

Fig. 17. Pressure gradient in a starve-fed TSE process allows for downstream unit operations 


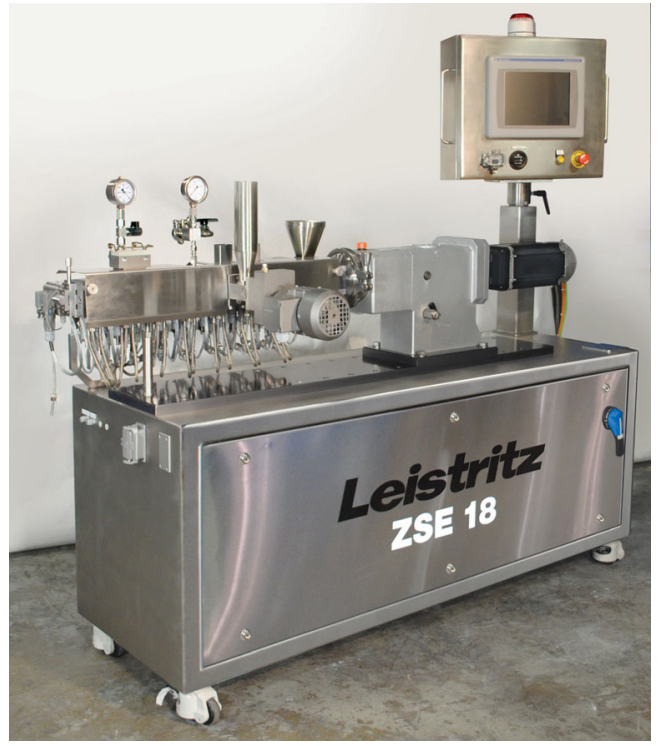

Fig. 18. Downstream side stuffing into the TSE process

processing. However, elevated pressure at the die results in temperature rise and is typically detrimental to the process (10). The following temperature rise formula is meant to be insightful (5).

$\Delta T\left({ }^{\circ} \mathrm{C}\right)=\Delta P($ bar $) / 2$

Where:

$\Delta P$ pressure rise at die

$\Delta T$ temperature rise at die

Pressure-generating devices can be mated to the twin screw extruder to help manage pressures and melt temperature. A positive displacement gear pump or single screw pump may be attached to the TSE to build and stabilize pressure to the die and would be typically used when extruding a transdermal film/patch and multifunctional medical tube or for micropellets. An example setup with gear pump as the pressure-generating device is presented in Fig. 19. Downstream systems now size and cool the extrudate with, once again, a multitude of high-tech equipment options available from the plastic and food processing technologies to make a high-quality, precision dosage form.

\section{Downstream Processing}

The next step is downstream processing. The most commonly used end product shapes for pharmaceutical applications are rods and films that are quenched on conveyors, film belt systems, or chill roll-pin breakers. Pellets can also be produced by a die face pelletizer. In general, strict geometric shaping is not often required because downstream equipment will mill the extruded material into a fine powder for further processing.

Multifunctional medical devices are also possible, such as for antimicrobial medical tubing or implantable drug delivery stents that require precision dies and shaping. Accurate control of part geometry will directly impact final part compliance of target product attributes. Cross-sectional area and internal geometry of the die relative to the mass flow rate determines the pressure generation requirement, which will directly influence melt temperature and performance for heat-sensitive products (11).

\section{Process Control Parameters}

Process control parameters are screw speed (rpm), feed rate, temperatures, and vacuum levels. Barrels house the screws and are temperature-controlled zones via PID temperature control algorithms. Typical readouts include melt pressure, melt temperature, motor amperage, and vacuum level. Near infrared (NIR), online viscosity, formulation imaging, and specialty probes can be integrated into the controls architecture as deemed beneficial. An example of laboratory-scale TSE with provision for probes along the path of the process section is presented in Fig. 20.

An important TSE parameter to track for any extrusion process is specific energy (SE) which reflects the amount of energy being input into the process and is calculated as follows:

Specific energy $(\mathrm{kW}$ perkg $/ \mathrm{h})=\frac{\mathrm{kW} \times \% \text { Torque } \times \mathrm{rpm}}{\mathrm{rpm} \text { rating } \times 0.97 \times Q(\mathrm{~kg} / \mathrm{h})}$

Where:

$\begin{array}{ll}\mathrm{kW} & \text { kilowatts (motor rating) } \\ \% \text { Torque } & \% \text { used of the maximum allowable torque } \\ \mathrm{rpm} & \text { screws rotations per minute } \\ \mathrm{rpm} \text { rating } & \text { maximum speed of the motor } \\ 0.97 & \text { gearbox efficiency } \\ Q & \text { feed rate }(\mathrm{kg} / \mathrm{h})\end{array}$

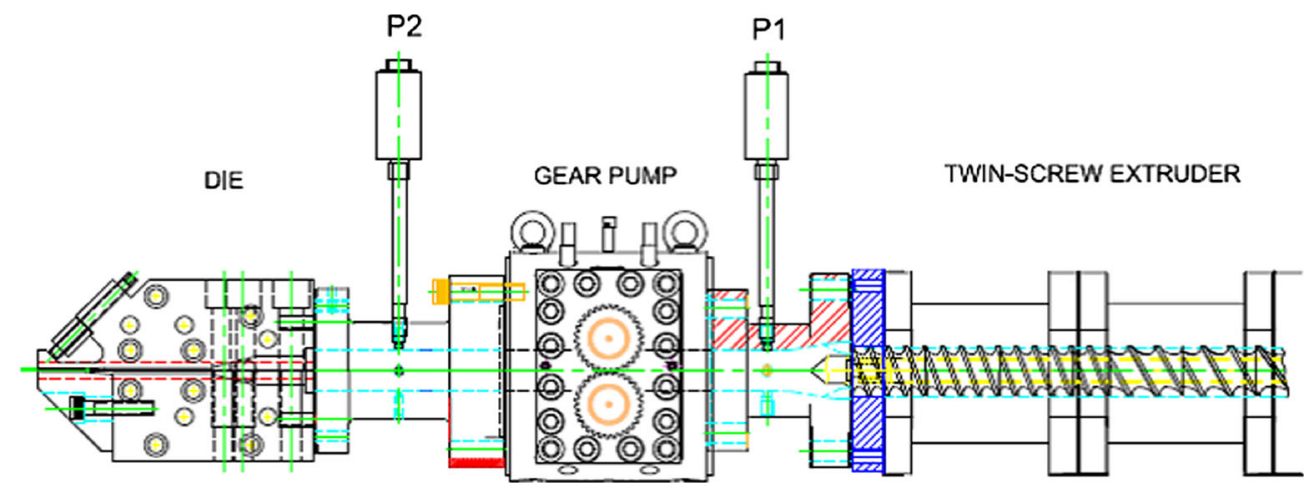

Fig. 19. TSE mated to a gear pump as positive displacement pumping device 


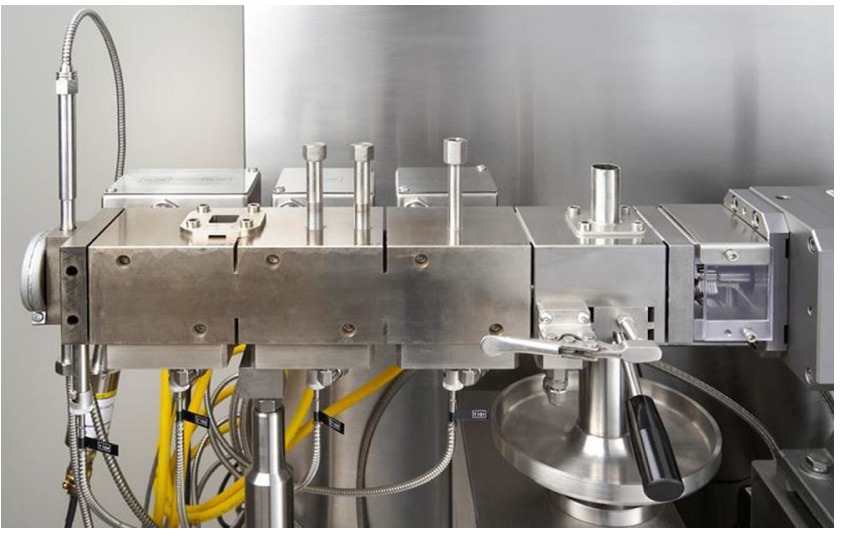

Fig. 20. Lab scale TSE with provision for probes for process monitoring

In a production setting, tracking SE is important as it is an indicator of any change to the process, whether it is hardware or materials related. If a TSE processes a given formulation at $0.25 \mathrm{SE}$ and it changes to 0.20 or $0.30 \mathrm{SE}$, something has changed and therefore the end product may be different too. SE also serves as a helpful scaling factor to determine operating parameters when scaling from a smaller to larger TSE.

\section{EVOLUTION AND CRITICAL DESIGN FEATURES FOR TSE'S}

\section{Controls and Instrumentation}

In the 1940s, control systems used manual devices such as hardwired push buttons with analog meters that used electromechanical relays to handle all the logic and interlocks. Direct current (DC) drives and motors were used to vary the speed of the screw rpms and other devices. In the 1990s, alternating current $(\mathrm{AC})$ drives began replacing DC because AC motors were less complicated and maintenance intensive. The usage of AC motors/drives steadily increased and now accounts for 98\% motors/drives below $1000 \mathrm{~kW}$.

Analog temperature controllers were used in early extruders with PID (proportional, integral, and derivative) control loops to control the temperature of each heating zone. The analog controller eventually evolved into digital temperature controllers employing microprocessors using software for PID algorithms. Temperature control algorithms are now imbedded in the programmable logic controller (PLC) code.

Monitoring gauges have always displayed screws' rpms, motor load, melt temperature, and pressure readings. The analog (dial) gauge has been around for 150 years. In the early 1980s, digital gauges were introduced, and today, many of the monitoring signals are brought into the PLCs so that logic can be programmed to provide different control features associated with these signals.

The PLC started to replace electromechanical relays in the 1960s and became commonly used on TSEs in the 1980s, when the man-machine interface (MMI) with graphics began to be used. In the early 2000s, the term man-machine interface became politically incorrect and evolved into human-machine interface (HMI) with alarming, recipes, data logging/trending and communications to other devices. In the last 10 years, the ability to link/integrate PLCs, referred to as distributive processing, has become available to integrate multiple subsystems into a fully functioning manufacturing cell (Palmer, 2015, Latest trend in programmable controller, personal communication).

TSEs often must adhere to FDA part 11 of Title 21 of the Code of Federal Regulations which defines the criteria under which electronic records are deemed trustworthy. Practically speaking, part 11 requires drug makers to implement controls, audits, and system validation for software and systems involved in processing electronic data. Protocols must be followed with regard to limiting system access to authorized individuals, operational checks, device checks, controls over systems documentation, and a plethora of other guidelines. Strict adherence with regard to copies of records and record retention is part of the guideline (12).

In the 1990s, PLC/HMI controls were avoided by pharmaceutical companies due to perceived validation difficulties. It was often deemed easier to validate a system with the 1980 s generation controls that more easily conformed to FDA regulations that were composed in the 1950s. Those days have thankfully passed. With a better understanding of the regulations and increased in-house IT acumen, the modern PLC/HMI controls architecture is now common in pharmaceutical environments.

Ironically, a starve-fed TSE is not a "precision device," so state-of-the-art controls, although beneficial, will have little effect on mixing performance. That being said, better controls, data acquisition, and communication functionalities only improve performance and insight into the process.

\section{Screws: Shafts (Torque), Metallurgies, Designs}

Rotating screws must be capable of transferring load from the motor to the elements to allow for successful processing. The motor transmits energy to the gearbox and then to the shafts, screw elements, and materials being processed. Screw shafts, upon which the elements are assembled, are typically the torque limiting factor to process materials.

Torque is determined by the cross-sectional area of the shaft, the geometry of the shaft, the metallurgy and hardening of the shaft, and the shaft geometry. Shaft technologies have evolved to allow smaller diameter shafts to transmit higher torques, facilitating a higher OD/ID ratio and therefore more volume. The following depicts the evolution of shafts used with segmented TSEs:

1. Key-way shaft - industry standard in 1950 - used with a $1.25 \mathrm{OD} / \mathrm{ID}$ ratio

2. Hexagonal shaft-industry standard in 1960 — used with a $1.4 \mathrm{OD} / \mathrm{ID}$ ratio

3. Splined shaft —industry standard in 1990 — used with a 1.55 $\mathrm{OD} / \mathrm{ID}$ ratio

4. Asymmetrical splined shafts - invented in 2005-used with a $1.66 \mathrm{OD} / \mathrm{ID}$ ratio

A graphic illustration of different shaft designs is presented in Fig. 21. The current state-of-the-art shaft design is an asymmetrical splined shaft manufactured of 17-4 stainless steel. The geometry of each "tooth" is such that the resulting tangential force vector is isolated, allowing a smaller diameter shaft to transmit higher torque as compared to previous designs. 


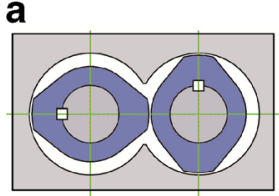

1.25 OD/ID RATIO (1950)

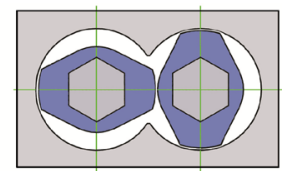

1.4 OD/ID RATIO (1960)

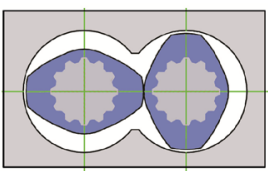

1.55 OD/ID RATIO (1990)

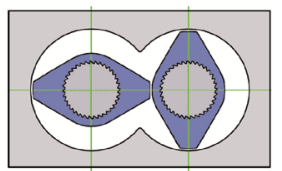

1.66 OD/ID RATIO (2005)

b

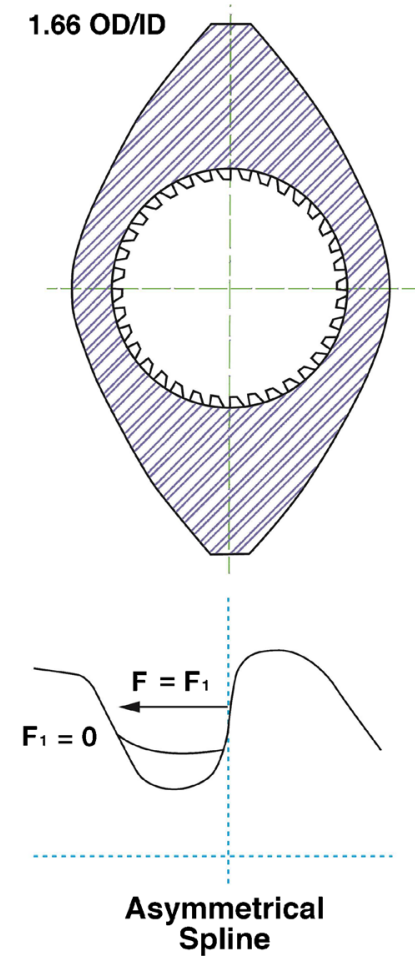

Fig. 21. a, b Evolution of shaft design and asymmetric spline shaft

One-piece screws (without shafts) are also possible for both corotating and counterrotating TSEs for higher attainable torques. Another plus of one-piece screws in a good manufacturing practice (GMP) environment is simplified cleaning, assembly, and validation procedures. A downside, particularly in an R\&D setting, is the lack of design flexibility inherent with a one-piece design. Just like barrels, metallurgies are matched to the application based on the degree of abrasion and corrosion resistance required.

\section{Barrels and Heating/Cooling}

In the 1950s, TSE barrels were generally made from one piece of steel and nitride hardened with a hardened depth ID less than $1 / 2 \mathrm{~mm}$ and external blowers for cooling. During this era, screw rpms were much lower so external cooling blowers were often more than adequate. In the 1970s and 1980s, screw rpms increased and modular barrels, typically 4 to $5 L / D$ each, became the accepted industry standard. The following is a brief overview of the evolution of barrel and heating/cooling designs for the modular design:

1. In the 1950s and 1960s, barrels were round with external air cooling via blowers.

2. In the $1970 \mathrm{~s}$, barrels became segmented in $4 \mathrm{~L} / \mathrm{D}, 5 \mathrm{~L} / \mathrm{D}$, and $10 L / D$ lengths and barrel liners became available.
3. In the early 1980 s, internal cooling bores for liquid cooling became the preferred design with improved heat transfer.

4. In the $1980 \mathrm{~s}$, barrels became square with plate heaters which resulted in better temperature control, and available metallurgies continued to expand, including replaceable barrel inserts/liners.

5. In the 1990s, barrels began to use cartridge heaters which offered higher wattage transference at less cost and improved maintenance.

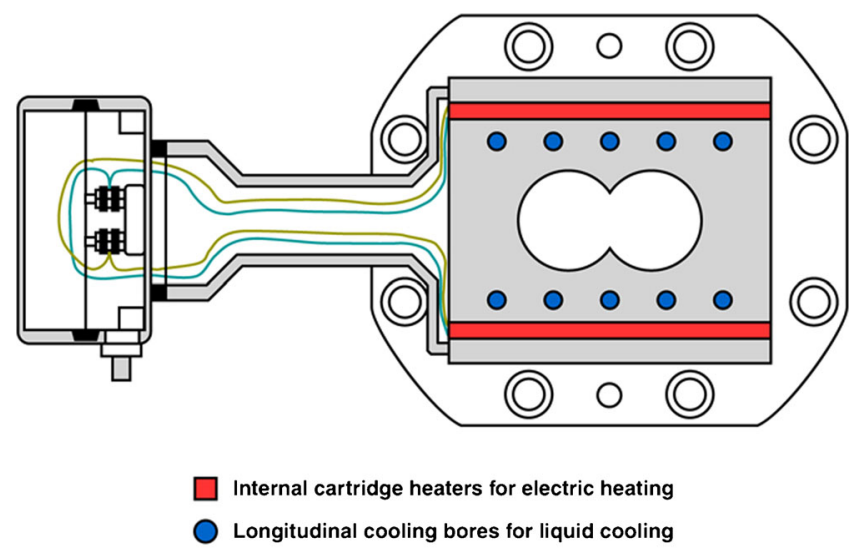

Fig. 22. End view of a state-of-the-art TSE barrel 
6. On or about 2005, barrels with two (2) cooling inlets/outlets became available that allowed higher flow rates and better heat transfer capabilities (13).

Modular barrels with internal cartridge heaters and internal cooling bores are deemed state of the art (Fig. 22). Internal cooling bores are close to the liner for maximum cooling effect and facilitate higher screw rpms and motor power without overheating. One-piece barrels offer better heat transfer capabilities, whereas barrel liners (Fig. 23) offer many metallurgical options. Due to the interaction with rotating screws, hardenable stainless steels are required for TSE barrels, as 300 series stainless steels generally have inadequate abrasion resistance. Nickel-based alloys are specified for increased corrosion resistance and powdered metallurgies (PM) for increased abrasion resistance.

\section{Gearboxes}

Historically, the gearbox was the weak link in the torque transmission train. A typical 1960s era extruder ran at much lower screw speeds and could only transmit $25 \%$ of the torque as compared to what is possible today. Due to the complexity of design and attainable part tolerances, gearbox failures were common. Significant improvements in the fields of metallurgy, heat treating, component design, and tolerances and the use of synthetic gear oil have dramatically improved torques, increased speeds, and decreased failures, making gearboxes essentially "bulletproof." Most failures occur due to either poor maintenance or a catastrophic event, such as a bolt going into the extruder.

\section{AVAILABLE MODES OF TWIN SCREW EXTRUDERS FOR PHARMACEUTICAL APPLICATIONS}

Twin screw extruders can be corotating or counterrotating and intermeshing or nonintermeshing. Screw configurations for various twin screw extruder are presented in Fig. 24. For the purpose of this article, these will be defined as low-speed late fusion (LSLF) twin screw extruders (run up to $50 \mathrm{rpm}$ ) and high-speed energy input (HSEI) twin screw extruders (run up to $1200+\mathrm{rpm}$ ). In a low-speed, late fusion process, the materials are not fully melted/fused until the latter part of the TSE process section, as compared to a high-speed, energy input process, where materials are melted and significant energy is imparted in the early part of the TSE process section.

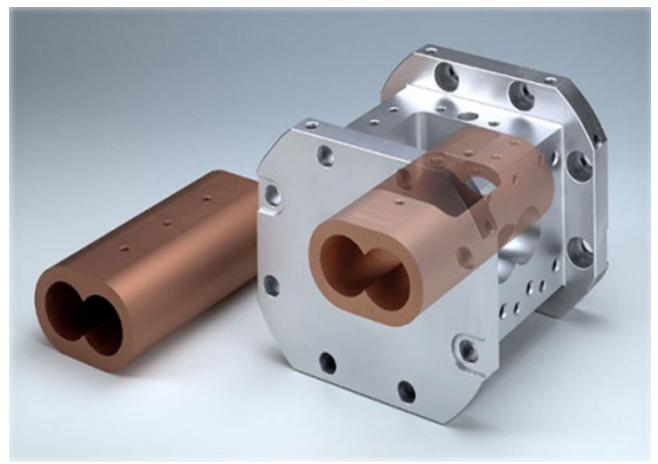

Fig. 23. TSE barrel liner outside and inserted into the barrel housing

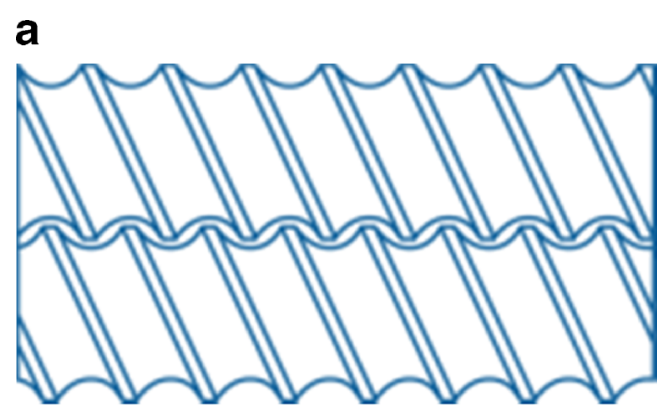

b

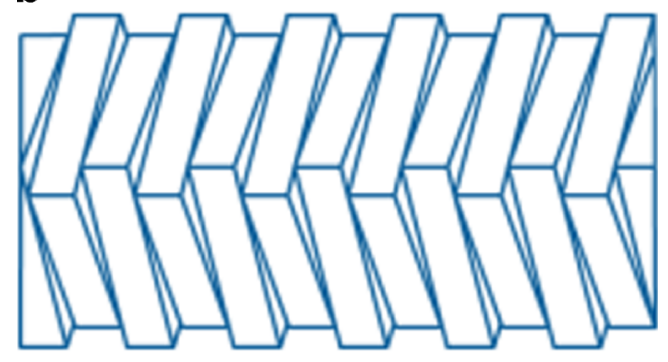

C

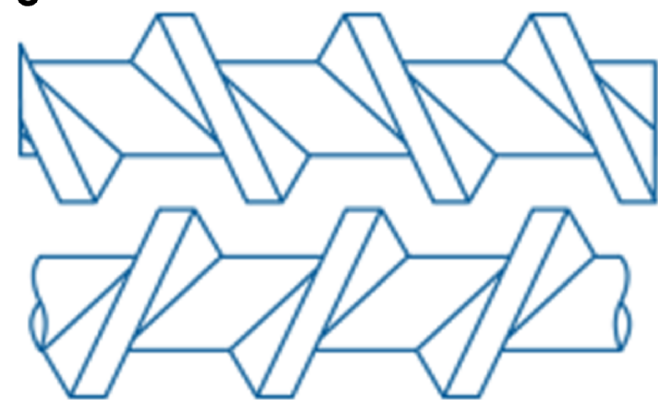

Fig. 24. Commercially available screw configurations for TSEs. a Intermeshing corotating; b Intermeshing counterrotating; c Nonintermeshing counterrotating

The following describes the current market status of each commercially available TSE with comments regarding their current and potential usage for pharmaceutical applications.

\section{Corotating Intermeshing Twin Screw Extruders}

The most widely used for the plastics and pharmaceutical industries is the HSEI corotating, intermeshing twin screw extruder. The screws are termed as "self-wiping," as surface velocities in the intermesh are in opposite directions, which causes the material to be "wiped" from one screw to the other and follow a figure 8 pattern along the length of the screws during processing. In corotation, the rotational clearances limit the lobe count to two (2) for standard flight depths, which are in the 1.5 to $1.8 \mathrm{OD} / \mathrm{ID}$ range.

Corotating intermeshing TSEs may utilize the latest splined shafts and/or one-piece screw designs for the highest torque transmittal possible. State-of-the art models integrate modular barrels with electric heating via cartridge heaters and internal cooling bores. Gearboxes also reflect the latest technologies available and facilitate screw rpms of $1200+$ and short process residence times-even $5 \mathrm{~s}$ or less is possible.

For a variety of technical and marketing reasons, the HSEI corotating TSE dominates the plastics, food, and 
pharmaceutical industries for mixing/mass transfer-intensive processes. Controlled pumping and wiping of the screws in combination with a modular design make this model an extremely versatile engineering tool, which is why this mode was embraced in the 1990s by plastics compounders, effectively ending early forays using single screw extrusion for this application. Since the corotating intermeshing TSE is a semidrag flow device with limited pumping/pressurization capabilities, a gear pump front-end attachment may be required for shape extrusion. It is expected that the corotating intermeshing mode will continue to lead the way for twin screw technology, which is not to say it's always the best choice.

\section{Counterrotating Intermeshing Twin Screw Extruders}

Counterrotating intermeshing twin screw extruders are available in either the high-speed, energy input configuration and or in a low-speed late fusing format. The LSLF intermeshing counterrotating mode of operation dominates the plastics industry for polyvinyl chloride shape extrusion of profiles with tens of thousands of worldwide installations. Interestingly, the HSEI intermeshing counterrotating TSE mode has proven superior for a number of pharmaceutical applications, as evidenced by an interesting 2012 study that compared corotation and counterrotation by Justin Keene and others for compounding of a poorly soluble API (14). As shown in Fig. 25, the counterrotating extruder was observed to form amorphous solid dispersions with a narrower residence time distribution.

A side-by-side comparison of the screw design for corotating and counterrotating TSE is presented in Fig. 26. A counterrotating intermeshing TSE shares many of the features/attributes of its corotating intermeshing TSE cousin, except the screws rotate in opposite directions and it feeds on two screws instead of one for corotation. Screws can be modular or one piece and OD/ID ratios are typically in the $1.5 / 1$ $\mathrm{OD} / \mathrm{ID}$ range. Barrels can be modular with internal coring for liquid cooling and also can use a one-piece design with blower air cooling, especially for low rpm versions. Screw rpms are generally lower as compared to corotation, with a maximum of approximately $600 \mathrm{rpms}$ for the high-speed version and less than $50 \mathrm{rpms}$ for the LSLF counterrotating TSE. a

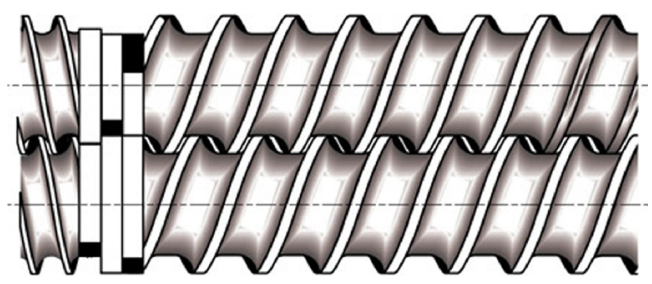

b

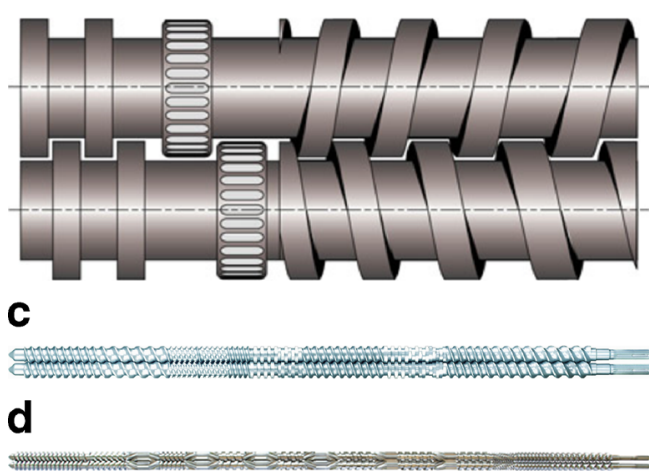

Fig. 26. Co- and counterrotating TSE screw elements. a Corotating; b Counterrotating; c Corotating; d Counterrotating

In counterrotation, in contrast to corotation, the surface velocities in the intermesh are in the same direction, which results in materials being forced up and through the screws, referred to as the "calender gap," where a very effective extensional mixing effect occurs. A top and end view of the calender gap is presented in Fig. 27. At higher screw speeds, the associated screw deflection effects result in metal-to-metal contact and wear and are what limits the attainable screws rpms, as compared to corotation.

In addition to the calender gap mixing effect, a wide variety of elements are available to facilitate mixing. Because the elements mesh similar to a gear, up to six lobes are possible at the same flight depth as bilobal corotating TSEs, which translates into more mixing events for each screw rpm. An example of a hexalobal mixing element for counterrotating intermeshing TSE is presented in Fig. 28. Also by displacing the mixing requirement exclusively from the calender gap to a more balanced mixing effect, higher screw rpms (600+) are possible (15).

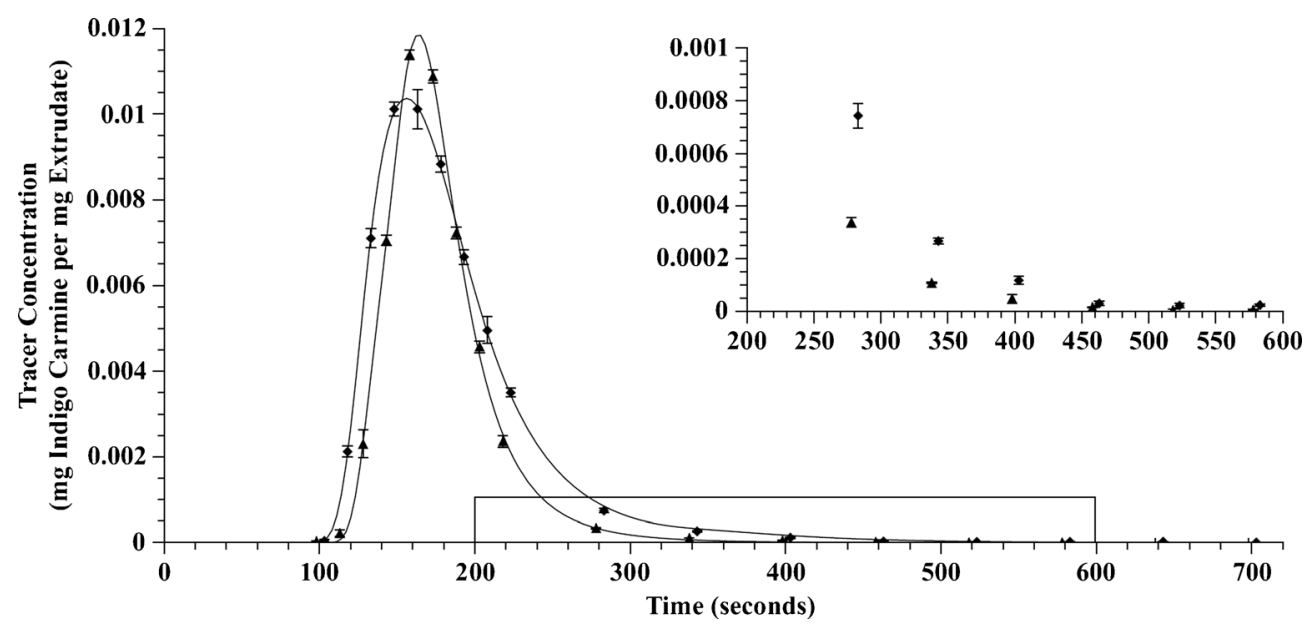

Fig. 25. Mean residence time and variance were all reduced in counterrotation when compared to the corotating TSE 
a
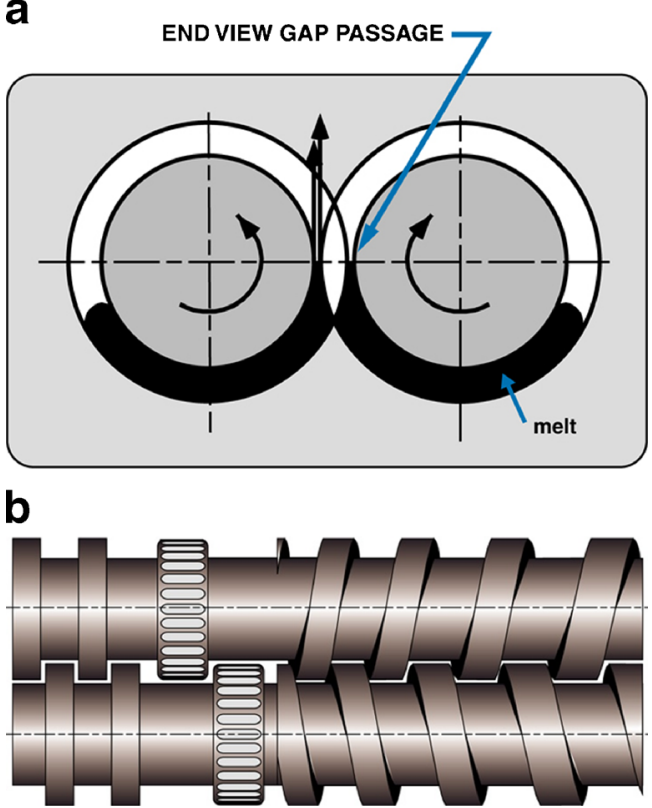

Fig. 27. a, b Top and end view of a calender gap of a counterrotating intermeshing TSE

In this TSE mode, positive displacement discharge elements may be specified to build and stabilize pressure to the die. Screw-to-screw flights are slanted in the same direction with minimal clearances/leakage in the nip region to facilitate a positive conveying. Only the counterrotating, intermeshing TSE provides these closed "C-shaped" chambers (Fig. 29), which essentially function as a positive displacement pump to the die and can eliminate the need for a gear pump.

In addition to the parallel design, conical LSLF counterrotating intermeshing TSEs (Fig. 30) are
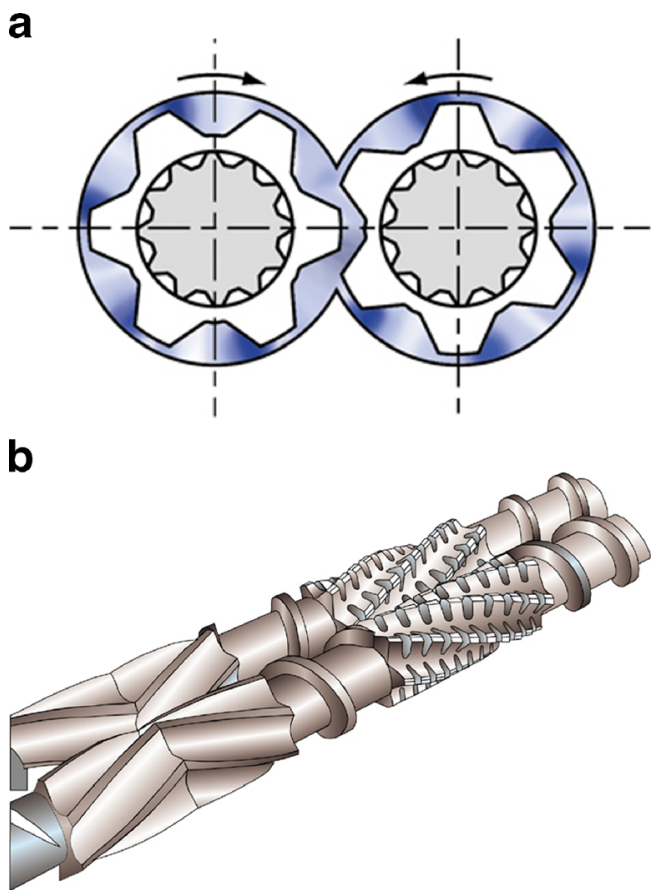

Fig. 28. a, b Examples of hexalobal mixing elements for counterrotating intermeshing TSE

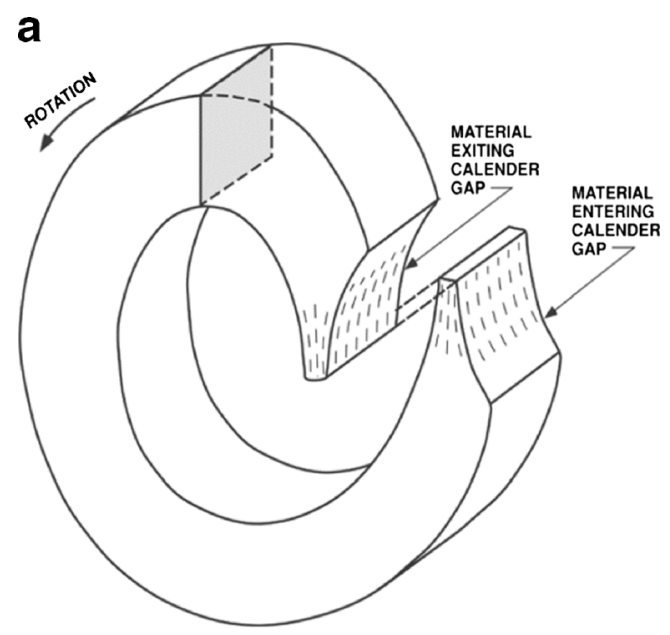

b

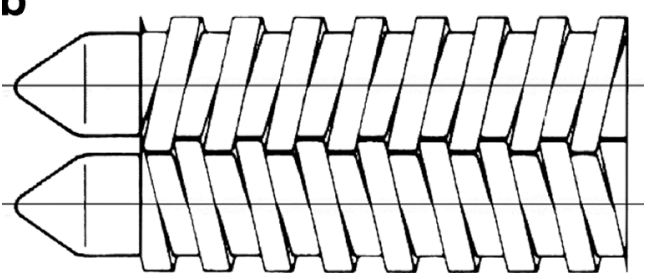

Fig. 29. a, b C-locked counterrotating discharge screws and the associated melt flow effect for counterrotating intermeshing TSE

manufactured where a large diameter feed zone has a continuous taper to the discharge end (or tips) of the screws. The small discharge diameter provides a low volume area with a positive pumping effect against die head pressures and also minimizes rotational shear and heat generation as the screws pump the material through the die. Conical LSLF counterrotating TSEs are currently not commercially available for pharmaceutical production applications.

The extensive worldwide usage of counterrotating intermeshing TSEs (probably 50\% + for plastics) suggests that this mode should be considered more frequently for pharmaceutical products. Possible benefits include better mixing at lower screw rpms, processing formulations with a tighter RTD, and improved pumping to the die. To date, most of the research activities have focused exclusively on the corotating TSE; however, the counterrotating TSE might prove to be a viable/preferred alternative.

\section{Counterrotating Nonintermeshing Twin Screw Extruders}

The counterrotating, nonintermeshing twin screw extruder utilizes side-by-side screws where the flight of one screw does not penetrate the fight depth of the second screw, which allows for unique design capabilities that can be mirrored, or dissimilar. A small root diameter (and larger flight depth) may also be specified in the feed area for feeding for low bulk density feedstocks. Similar to a single screw extruder, the root

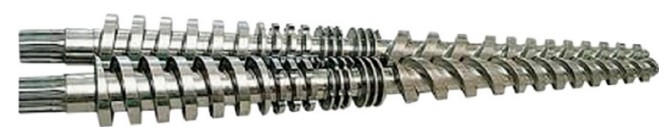

Fig. 30. Processing section of a conical intermeshing counterrotating TSE 
diameter can be tapered up after the feed section to compress and melt the polymer. Screw elements include forward or reverse flights, different helix angles, thick or thin flight thicknesses, multiple screw starts, and other single screw design features. Screw elements can be matched or staggered at different points along the process length to facilitate pumping and/or mixing. Various screw configurations for counterrotating nonintermeshing TSEs are presented in Fig. 31.

A typical process length for this TSE mode is 30 to $60: 1 \mathrm{~L} /$ $D$ with screw rpms up to 500. Due to the absence of an intermesh and the associated geometric limitations, the nonintermeshing mode may be specified at 100+:1 L/D, which allows for long RTs which may be beneficial for some processes, i.e., high-level devolatilization processes. The lack of an intermesh is problematic for dispersive mixing applications as intermesh and apex zones are gentler than in the intermeshing designs, and the self-wiping effects inherent with intermeshing geometries are also somewhat lacking.

The geometric freedom inherent with nonintermeshing screws has been largely untapped. Into the early 1990s, the nonintermeshing counterrotating TSE was still deemed viable for many plastic products, but due to the lack of development efforts for hardware (i.e., screws are segmented via triple start threads), process research and marketing efforts for this mode have faded from commercial acceptance. That being said, the HSEI counterrotating nonintermeshing TSE is still preferred for some niche applications. Pharmaceutical class GMP models are currently not available, although its attributes might offer benefits for atypical processes (16).

\section{HISTORY OF TWIN SCREW EXTRUSION FOR PHARMACEUTICALS}

Interest in extrusion by the pharmaceutical industry began in the 1980s. Some early work was performed by Goedecke $\mathrm{GmbH}$ in Germany that led to the installation of a 50-mm class corotating TSE for a melt granulation process. The machine supplier, Leistritz, struggled with the paperwork and wondered why Goedecke chose such a funny color for the equipment, but not much more and was unaware that a new market was beginning to unfold. The extrusion equipment remains in production today.

The case study of Rezulin ${ }^{\mathrm{TM}}$, the first drug manufactured via melt extrusion, provides enlightening history. In 1989, Isaac Ghebre-Sellassie of Parke-Davis/Warner-Lambert (PD/ WL) was asked by management to convert a spray dried process for the solubilization of a poorly soluble drug substance, troglitazone, to an alternative organic solvent-free manufacturing. The spray drying process had been initially selected after all commonly used methods (fusing method, hot melt/solvent evaporation, and solvent evaporation process) were evaluated in order to improve the bioavailability of troglitazone. However, the drug substance and processes that included melting had to be abandoned, prompting atypical methodologies to be considered and resulted in a laboratory-scale twin screw extruder being installed in the PD/WL labs.

As a result, the PD/WL staff began to explore melt extrusion as an alternative process that generated an amorphous dispersion of the drug in a polymeric matrix and simultaneously ensured the stability of the drug substance during processing. Since the TSE was available and recognized to offer superior mixing capabilities with a short residence time, a decision was made to assess the melt extrusion (ME) process. The formulation and process were optimized using a Leistritz 34-mm TSE without degradation of the drug substance even when the formulation was processed above the melting temperature of the drug substance, due to the short residence time in the TSE of less than $1 \mathrm{~min}$.

The Rezulin ${ }^{\mathrm{TM}}$ process, as it became known, was then transferred to a Leistritz 50-mm production scale TSE, and the product approved by the FDA and introduced in 1997, becoming the first commercial product that utilized $\mathrm{ME}$ as a solubility enhancement manufacturing process. Interestingly, the initial batch size was $250 \mathrm{~kg}$. Due to the consistency and reproducibility of the product, the batch size was eventually increased to $5000 \mathrm{~kg}$ over $500 \mathrm{~h}$. During the time the product was in the market, there were no batch failures. A US patent for the formulation and process was issued in 2004 (US Patent 6,677,362) (Ghebre-Sellassie, 2015, Adoption of twin screw extrusion by pharmaceutical industry, personal communication). Somewhat similar work was performed in Europe by companies such as Knoll (later Abbott and Soliqs), Mundiepharma, and Napp (Steiner, 2015, Adoption of twin screw extrusion by pharmaceutical industry, personal communication).

Simultaneously in the early 1990s, under the auspices of Jim McGinity and the University of Texas (UT), vigorous and varied research efforts were exerted to develop alternative processes to solvent evaporation for the preparation of transdermal and transmucosal film delivery systems, which spawned UT's first poster at the annual meeting of AAPS in 1994. Early success with the acrylic polymers was followed by work to prepare granules, pellets, and tablets with a wide variety of polymers and lipids (McGinity, 2015, Investigation of twin screw extrusion by pharmaceutical scientists in academia, personal communication).

During this timeframe, UT graduates (John Koleng, Feng Zhang, Michael Crowley, and others) became the nucleus of the management team at PharmaForm, a UT incubator company that led pioneering efforts using melt extrusion as a manufacturing platform. At this time, melt extrusion technology became recognized as a viable manufacturing platform.
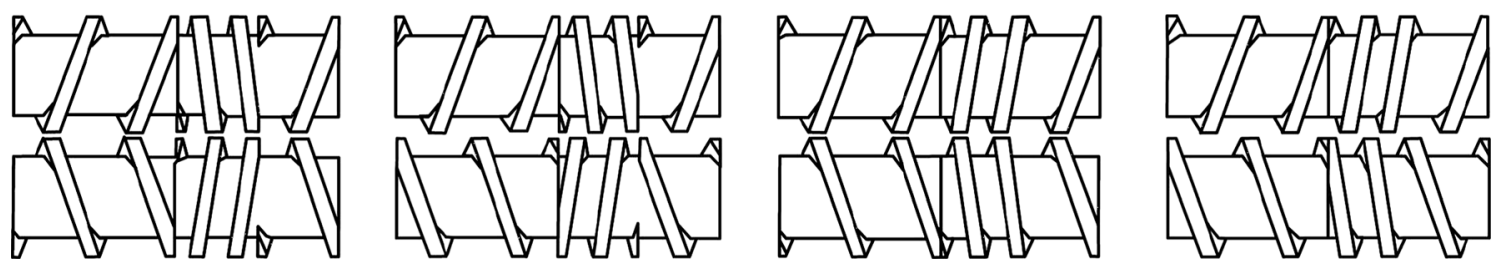

Fig. 31. Different screw configurations for counterrotating nonintermeshing TSE 
In 2003, the first book on the subject matter, Pharmaceutical Extrusion Technology, edited by Isaac Ghebre Selassie and Charles Martin, was published by Informa Healthcare. In addition to some of the early pioneers from the pharmaceutical world, many of the chapters were written by extrusion experts from the plastics industry, focusing upon extrusion engineering principles.

Then a spark! The FDA's 2004 Process Analytical Technology (PAT) initiative provided drug makers a framework for pharmaceutical development, manufacturing, and quality assurance through inline monitoring (17). In a nutshell, the PAT initiative encouraged that extrusion be considered for the manufacture of new dosage forms-the PAT initiative could have, literally, been written by a TSE equipment supplier since it denotes attributes inherent with that device and continuous processing.

Another solubility enhanced product that was approved by the FDA was Kaletra ${ }^{\mathrm{TM}}$, which was a reformulation of a drug to treat HIV that provided a robust dosage form that did not require refrigeration to maintain stability (18). Kaletra $^{\mathrm{TM}}$ applied melt extrusion technology to improve the overall therapeutic efficacy of a drug, and currently represents the most commercially successful melt-extruded dosage form to enhance oral bioavailability of poorly watersoluble drugs.

Now the activities relating to melt extrusion activity really began to accelerate. The seeds had been planted from the early development work at Parke-Davis, the ground had been fertilized at research institutions like the University of Texas to develop an understanding of melt extrusion, and the FDA's 2004 PAT initiative had provided the germination effect that allowed melt extrusion usage to expand. In the early 1990s, there were only a handful TSE pharmaceutical class installations worldwide. In the next 10 years, this number would dramatically increase into all niches of the pharmaceutical landscape, ranging from universities to large pharmaceutical companies, with CROs, CMOs, and generic drug companies all becoming users of melt extrusion.
By 2010, almost every major pharmaceutical company had installed TSEs into their R\&D equipment portfolios. The use of SSEs had faded, as the comparative utility of TSEs for mixing and devolatilization became apparent. Research efforts across the board were intensified and several amorphous compositions were commercialized leading to the general acceptance of melt extrusion as a viable technology.

In the last dozen years, Merck has become a leading proponent and has evolved into a leading edge innovator introducing, developing, and promoting various extrusion-related technologies in the areas of foaming, devolatilization, shape extrusion, and computer modeling. Novartis, GSK, BASF, Evonik, Dow Chemical, Grunenthal, and Ashland have all been active in developing and marketing extrusion processes. Bend Research, PharmaForm (now Formex), ExxPharma Therapeutics, Rottendorf, and Foster Delivery Science are examples of companies that offered contract services early on, with the list growing to 40 plus worldwide. In addition to the University of Texas, early research efforts began at the University of Mississippi and Massachusetts Institute of Technology, followed by St. Johns, New Jersey Institute of Technology, University of Pittsburgh, Instituto de Capacitación del Plástico y del Caucho (ICIPC), NOLL GmbH, Halle Plastic GmbH, and others.

While the majority of melt extrusion applications have focused on the oral delivery of poorly soluble drugs, commercially marketed melt-extruded products are already available which have changed the drug delivery paradigm. The most well-known is NuvaRing (Merck-Schering Plough) which uses a coextrusion process to imbed the API into an ethylene vinyl acetate (EVA) core matrix (19). Another melt-extruded shaped system is abuse-deterrent oral tablets for opioids (20). There are currently development efforts being expended for transdermal patches, dissolvable films, foamed, and coextruded products that are made by the extrusion process. These products represent the most novel of melt extrusion developments. A list of commercial products manufactured using twin screw melt extrusion process is presented in Table I. There's more to come.

Table I. Commercial Drug Products Manufactured Using Twin Screw Extruder

\begin{tabular}{|c|c|c|c|}
\hline Product & Indication & HME purpose & Company \\
\hline Rezulin (troglitazone) & Diabetes & Amorphous dispersion & Wyeth \\
\hline Onmel (itraconazole) & Antifungal & Amorphous dispersion & Merz North America, Inc. \\
\hline Zoladex (goserelin acetate) & Prostate cancer & Shaped system & AstraZeneca \\
\hline Implanon (etonogestrel) & Contraceptive & Shaped system & Merck \\
\hline Lacrisert (HPC Rod) & Dry eye syndrome & Shaped system & Merck \\
\hline Gris-PEG (griseofulvin) & Antifungal & Crystalline dispersion & Pedinol Pharmacal \\
\hline Palladone (hydromorphone $\mathrm{HCl}$ ) & Pain & Controlled release & Purdue Pharma \\
\hline Nucynta (tapentadol) & Pain & Controlled release & Janssen \\
\hline Opana ER (oxymorphone $\mathrm{HCl}$ ) & Pain & Controlled release & Endo Pharmaceuticals \\
\hline NevaRing (etonogestrel, ethinyl estradiot) & Contraceptive & Shaped system & Merck \\
\hline Norvir (ritonavir) & Antiviral (HIV) & Amorphous dispersion & AbbVie \\
\hline Kaleatra (ritonavir/lopinavir) & Antiviral (HIV) & Amorphous dispersion & AbbVie \\
\hline Eucreas (vildagliptin/metformin $\mathrm{HCl}$ ) & Diabetes & Melt granulation & Novartis \\
\hline Zithromax (azithromycin) & Antibiotic & Melt granulation & Pfizer \\
\hline Orzurdex (dexamethanone) & Macular edema & Shaped system & Allergan \\
\hline Noxafil (posaconazole) & Antifungal & Amorphous dispersion & Merck \\
\hline Belsomra (suvorexant) & Medication for insomnia & Amorphous dispersion & Merck \\
\hline
\end{tabular}




\section{CONCLUSION}

Before the twin screw extruder was deemed the best continuous mixer by the plastics community, other devices (i.e., single screw extruders) were utilized. The superior mixing characteristics inherent with a TSE allowed this device to dominate other continuous mixers and spurred intensive development efforts and experimentation that spawned highly engineered formulations for the commodity and high-tech plastic products we use every day. Today, twin screw extrusion is a battle hardened, well-proven, manufacturing process that has been validated in 24-h/day industrial settings for more than half a century. What would our lives would be like without plastics that were compounded on TSEs?

The evolution of melt extrusion in the pharmaceutical industry resembles what has occurred for plastics. TSE designs for pharmaceutical applications replicate the staging of unit operations and mixing mechanisms used for plastics, and the extensive development and long-standing production principles learned by the plastics industry have allowed quick implementation of proven technologies to pharmaceutical processes, i.e., Rezulin ${ }^{\mathrm{TM}}$. The TSE process is a well-known entity.

New extrusion technologies being applied to advanced drug delivery systems have risen to the forefront of pharmaceutical products and allowed targeted and alternative delivery systems. In the design of such systems, melt extrusion and the supporting downstream systems can make almost any shape to facilitate to unique dissolution profiles.

TSE suppliers have now downsized and redesigned equipment for GMP environments, and additional efforts have been made to design TSE systems to test early-stage materials available only in limited quantities. Coextruded products utilizing multiple extruders and integration with inline molding represent the next generation of development efforts. These efforts will also be based upon proven technologies that have been used for decades in the plastics industry.

With so many drug candidates having solubility issues, it is clear that melt extrusion will continue to play a significant role in producing amorphous molecular dispersions of these new chemical entities. The plastics industry embraced continuous processing to make better, more consistent products at a lower cost, and now pharmaceutical companies are doing the same and reaping the benefit of $100+$ years of those efforts. As pharmaceutical scientists become more familiar with this technology and the equipment, we will continue to see an expanding number of extrusion-related publications, patents, and new products.

Led by the twin screw extruder, the "extrusion evolution" will continue. The best indication of the future is the past. The future is bright and the path is well proven. It's deja vous all over again.

\section{REFERENCES}

1. Gray M. British Patent 5056; 1879.

2. White JL, Bumm SH. Perspectives on the transition from batch to continuous mixing technologies in the compounding industry. Int Polym Process. 2010;25(5):5.

3. Veris Consulting. Year-end machinery reports. Society of Plastics Industry, 2014.

4. Thummert $\mathbf{M}$, editor Dispersive mixing in co-rotating twin screw_-principles and examples. Leistritz Twin Screw Extrusion Workshop; 2011; Clinton, NJ.

5. Todd D. Reactive extrusion-thermo, theory, and reality. Leistritz Twin Screw Extrusion Workshop; 2010; Clinton, NJ.

6. Thiele W. Twin screw extrusion and screw design. In: GhebreSellassie I, Martin C, editors. Pharmaceutical extrusion technology. 1st ed. Boca Raton: CRC; 2003. p. 69-78.

7. Martin C. Processing thermoplastic urethanes via twin screw extrusion. In: Szycher M, editor. Szycher's handbook of polyurethanes. 2nd ed. Boca Raton: CRC; 2013. p. 865-88.

8. DiNunzio JC, Martin C, McGinity JW, Zhang F. Melt extrusion. In: Miller DA, Watts AB, Williams RO, editors. Formulating poorly water soluble drugs. 1st ed. New York: Springer; 2012. p. 311-62.

9. Jerman R, editor. Devolatilization of polymers via twin screw extrusion. Proceedings of the Leistritz Twin Screw Extrusion Workshop; 2006; Bridgewater, NJ.

10. Todd D, Zhu L, editors. Polymer devolatization. Leistritz Twin Screw Extrusion Workshop; 2013; Clinton, NJ.

11. Szycher $\mathbf{M}$, editor. Intelligent antimicrobial products via twin screw extrusion. Leistritz Twin Screw Extrusion Workshop; 2015; Clinton, NJ.

12. Part 11, Electronic records: electronic signatures-scope and application. U.S. Food and Drug Administration; 2003.

13. Ghebre-Sellassie I, Martin C. Future trend. In: Ghebre-Sellassie I, Martin C, editors. Pharmaceutical extrusion technology. Boca Raton: CRC; 2003. p. 383-92.

14. Keen JM, Martin C, Machado A, Sandhu H, McGinity JW, DiNunzio JC. Investigation of process temperature and screw speed on properties of a pharmaceutical solid dispersion using corotating and counter-rotating twin-screw extruders. J Pharm Pharmacol. 2014;66(2):204-17.

15. Thiele W. Counterrotating intermeshing twin-screw extruders. In: Todd D, editor. Plastics compounding equipment and processing. 1st ed. Brookfield: Hanser/Gardner; 1998. p. 47-70.

16. White JL. Flow mechanisms and modeling of non-intermeshing counter-rotating twin screw extruders. In: White JL, editor. Twin screw extrusion: technology and principles. New York: Hanser; 1990. p. 110-30.

17. A framework for innovative pharmaceutical development, manufacturing and quality assurance. U.S. Food and Drug Administration; 2004.

18. Klein CE, Chiu YL, Awni W, Zhu T, Heuser RS, Doan T, et al. The tablet formulation of lopinavir/ritonavir provides similar bioavailability to the soft-gelatin capsule formulation with less pharmacokinetic variability and diminished food effect. J Acquir Immune Defic Syndr. 2007;44(4):401-10.

19. Laarhoven JAH, Kruft MAB, Vromans H. In vitro release properties of etonogestrel and ethinyl estradiol from a contraceptive vaginal ring. Int J Pharm. 2002;232:163-73.

20. Bartholomaeus JH, Arkenau-Maric E, Galia E. Opioid extendedrelease tablets with improved tamper-resistant properties. Expert Opin Drug Deliv. 2012;9(8):879-91. 